Research Article

\title{
Experimental and Numerical Simulation Study on the Antipenetration Properties of Fiber Ceramic-Reactive Powder Concrete Composite Targets
}

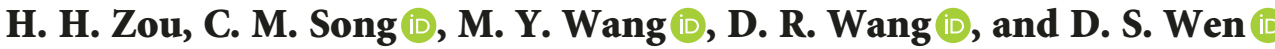 \\ State Key Laboratory of Disaster Prevention \& Mitigation of Explosion \& Impact, Army Engineering University of PLA, \\ Nanjing 210007, China \\ Correspondence should be addressed to C. M. Song; ming1979@126.com
}

Received 14 August 2018; Revised 7 November 2018; Accepted 13 November 2018; Published 7 March 2019

Academic Editor: Yuri S. Karinski

Copyright (c) 2019 H. H. Zou et al. This is an open access article distributed under the Creative Commons Attribution License, which permits unrestricted use, distribution, and reproduction in any medium, provided the original work is properly cited.

Composite materials have been demonstrated to possess excellent antipenetration capacities, but the existing studies have not involved the penetration characteristics of ceramic-concrete composite targets. To investigate the antipenetration mechanisms of fiber ceramic-reactive powder concrete (FC-RPC) composite targets, three pieces of FC-RPC composite targets were designed to perform penetration tests. Antipenetration tests were performed with a special howitzer with a diameter of $125 \mathrm{~mm}$. The test parameters, such as the impact velocity, failure pattern of projectiles, penetration depth, crater diameter, and failure model of targets, were obtained. It was found that the FC-RPC targets exhibited an excellent antipenetration capacity and failed in a ductile manner, the target caused an obvious erosion effect on projectiles at low speed (i.e., $375 \mathrm{~m} / \mathrm{s}$ ), and the antipenetration performance of the composite target was improved by increasing the thickness of the FC target. Simultaneously, numerical simulations of FCRPC targets subjected to projectile impact were carried out by using LS-DYNA codes. Separately, combined and integrated finite element models were used to analyze the effect of the fiber layer in the composite target. The numerical results of the combined model were in good agreement with the experimental data, and the reliabilities of simulation were validated. The differential protection factor of the FC-RPC targets was obtained based on the penetration tests and numerical simulation, and an empirical formula for multilayer targets was presented.

\section{Introduction}

As a result of increased concerns regarding public safety in recent years, the resistance of the protective structure to impact and penetration has attracted much interest [1]. A variety of new materials and composite structures have been intensively studied and applied to protective structures, such as fiber concrete [2], reactive powder concrete (RPC) [3], and corundum-rubble concrete [4], which effectively improve the antipenetration ability of the protective structure. Ceramic material possesses high strength, high hardness, and low density [5] and has been widely used in the field of armor. It was shown that ceramic as an armor material not only provides excellent effective penetration resistance at the current projectile level $(<1.8 \mathrm{~km} / \mathrm{s})$ but also provides a considerable antipenetration protection potential in the future projectile level $(2.5-3 \mathrm{~km} / \mathrm{s})$ [5]. Therefore, the application of ceramic materials in protective engineering is expected to further enhance the antipenetration capability of traditional concrete protective structures.

Many studies on the penetration of armored ceramics have been conducted, such as depth of penetration (DOP) tests, theoretical models, and numerical simulation [5-10]. Therefore, some profound understandings of the complex response process and mechanism of penetration have been obtained. The main role of the ceramic is to blunt, shatter, and erode the projectile, while the main disadvantage of ceramic is brittleness. Thus, the ceramic tile is often backed with ductile materials, such as armored steel, aluminum, or fiberglass, capable of dispersing and absorbing kinetic energy, for composite targets. Sherman [6] conducted a 
number of investigations into the antipenetration performance of alumina ceramics with different thicknesses of steel, aluminum, and fiber-reinforced backplane. It was indicated that the dynamic damage caused by the reflected stress waves on the steel backplane is the smallest, followed by the aluminum alloy backplane. Many investigators have also attempted to improve the brittleness of ceramics through restraint. Franzen et al. [7] found that the antiballistic performance of ceramics increased with the degree of lateral restraint. Sherman and Ben-Shushan [8] studied the mechanism of restraint on the ballistic resistance of ceramics. The results showed that the restraint reduced the radial cracks of ceramics and restrained the circumferential cracking and fragmentation of ceramic cones, and ballistic resistance increased with the degree of lateral restraint. Anderson and Morris [9] presented empirical formulas to maximize the antiballistic performance of ceramics considering the degree of lateral restraint. Zaera et al. [10] investigated the effect of the bonding layer in the ceramic/ metal composite armor. It was concluded that the presence of the bonding layer caused a wider range of plastic deformation of the metal back plate to consume more projectile energy.

Because most of the protection engineering structures are concrete structures, the ceramic materials must be applied in the form of a composite structure with the concrete structure, the antipenetration performance of which needs to be reevaluated. However, limited research has been performed on the antipenetration performance of ceramicconcrete composite targets. On the contrary, high strength concrete should be considered for ceramic recombination because of the high strength of ceramic. RPC is a type of concrete material with high strength, high toughness, and low porosity [3]. Experimental studies on RPC targets under projectile impacts have been conducted in [11]. The results indicated that the antipenetration ability was three times as that of ordinary concrete. Therefore, RPC could be used as the preferred material for compositing with ceramics.

In this paper, three pieces of fiber ceramic-reactive powder concrete composite targets (FC-RPC) were designed, which were proposed to enhance the antipenetration capability of traditional concrete targets. The antipenetration performance of FC-RPC targets was studied by the DOP penetration test and numerical simulations. The experiments were carried out with the help of a howitzer, and the numerical simulations were performed with the commercial finite element code LS-DYNA, which enabled further assessment of the experimental findings. Then, an empirical formula for multilayer targets was further presented.

\section{Penetration Tests}

\subsection{Materials}

2.1.1. Projectile. As shown in Figures 1 and 2, the ogive nose projectiles used in the penetration tests were machined from $35 \mathrm{CrMnSiA}$ steel rods, the yield strength of which was $1280 \mathrm{MPa}$. The inner parts of the projectile were filled with quartz sand, and the mass of the projectile was $25.88 \mathrm{~kg}$. The

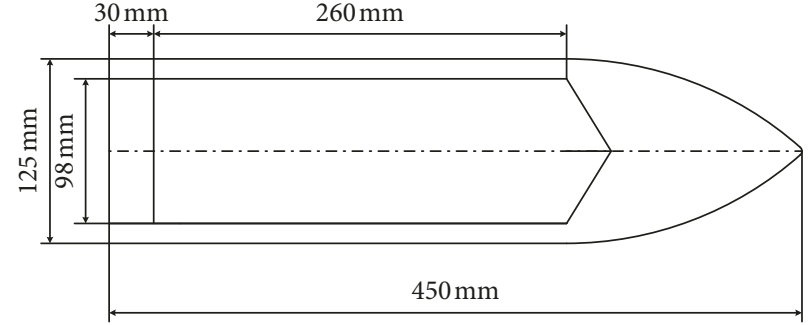

FIgURE 1: The scheme of the projectile.

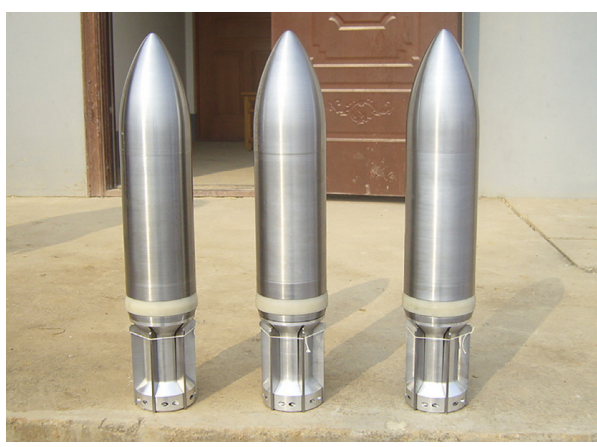

Figure 2: Projectiles.

length and diameter of the projectile were $450 \mathrm{~mm}$ and $125 \mathrm{~mm}$, respectively. The projectile length to diameter ratio and CHR were 1.28 and 1.89 , respectively. During the tests, the projectiles were launched by a $125 \mathrm{~mm}$ diameter howitzer at striking velocities ranging from $350 \mathrm{~m} / \mathrm{s}$ to $400 \mathrm{~m} / \mathrm{s}$.

2.1.2. Target Fabrications. Figure 3 shows the FC-RPC targets used in the test, which were composited of a Fiber Ceramic (FC) target and RPC target. To ensure the fixation between the FC target and the RPC target and eliminate the structural gap, the FC target was bonded on the front surface of the RPC target by strong glue. The FC target was made of $\mathrm{Al}_{2} \mathrm{O}_{3}$ ceramic and glass fiber, as shown in Figure 4. The transverse dimension of the FC target was $2000 \mathrm{~mm} \times$ $2000 \mathrm{~mm}$. The configurations of the FC targets used in the penetration tests are shown in Table 1 . The content of $\mathrm{Al}_{2} \mathrm{O}_{3}$ in ceramic materials was $90 \%$, the mechanical property parameters of ceramic materials were tested by the relevant national standards of China, and the test results are shown in Table 2. The mechanical property parameters of the fiber are also shown in Table 2.

The RPC target can provide strong support for the FC target to prevent the tensile fracture caused by the overall bending deformation and then ensure the antipenetration performance of the FC target. According to the existing research results [11], a 5\% volume fiber ratio of the RPC target was used in this paper. The mix of RPC was also the same as in [11]. The RPC target was cast into a cylinder with a diameter of $1600 \mathrm{~mm}$ and a length of $2000 \mathrm{~mm}$. To eliminate the boundary effect, the target was tightened with a $3 \mathrm{~mm}$ thick steel plate. Compared with the penetration depth of the projectile in the target body, the RPC target was relatively thick and can be considered as a semi-infinite 


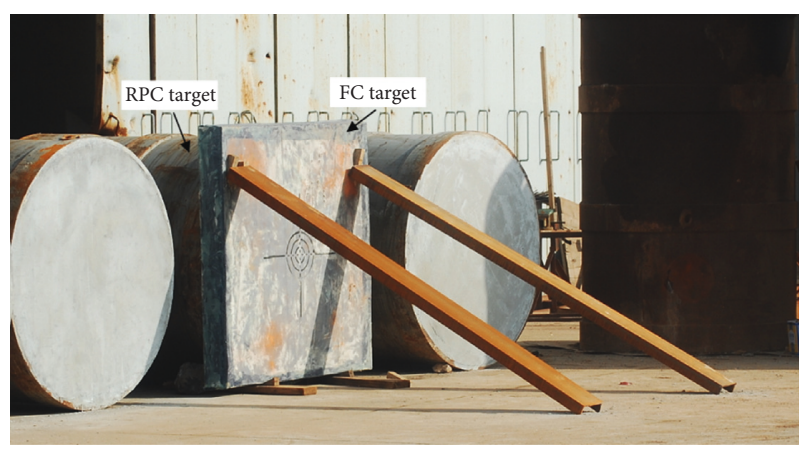

FIGURE 3: FC-RPC composite target.

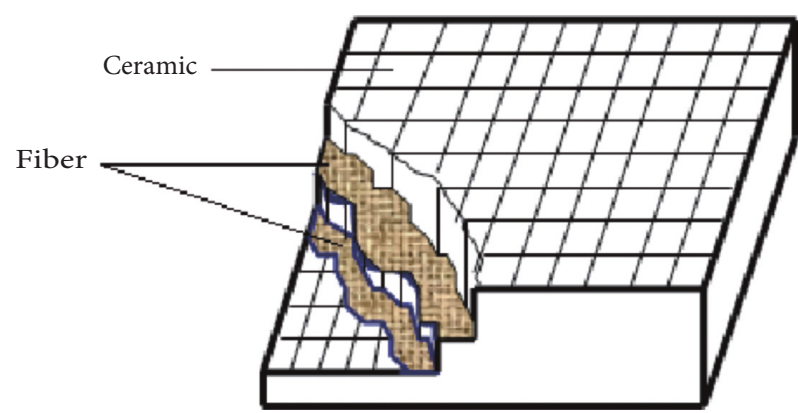

FIgURe 4: The composition of the FC target.

TABle 1: Configurations of the FC targets.

\begin{tabular}{lcccc}
\hline No. $\begin{array}{c}\text { Number of the } \\
\text { ceramic } \\
\text { blocks layer }\end{array}$ & $\begin{array}{c}\text { Number of } \\
\text { the fiber } \\
\text { layer }\end{array}$ & $\begin{array}{c}\text { Total thickness } \\
\text { of the ceramic } \\
\text { block }(\mathrm{mm})\end{array}$ & $\begin{array}{c}\text { Thickness } \\
\text { of FC } \\
\text { targets } \\
(\mathrm{mm})\end{array}$ \\
\hline 1 & 8 & 9 & 160 & 178 \\
2 & 5 & 6 & 100 & 112 \\
3 & 3 & 4 & 60 & 68 \\
\hline
\end{tabular}

target. The mechanical properties of RPC are shown in Table 3. The compressive strength of RPC is $176 \mathrm{MPa}$, which is similar to that reported by Wang et al. [11] and Tai [12].

2.2. Emission and Measures. The penetration test system included a $125 \mathrm{~mm}$ special howitzer, projectile velocity measurement system, and high-speed photography. An arrangement diagram of the test is shown in Figure 5. The FC-RPC target was approximately $50 \mathrm{~m}$ from the outlet of the howitzer, and two broken copper mesh targets were installed at a distance of $40 \mathrm{~m}$ from the howitzer. The targets faced the howitzer and were perpendicular to the ground to make sure that projectiles impact targets vertically. The high-speed photography was located on the side of the howitzer, which was used to capture the impact posture of the projectile. The target velocity was expected to be between 350 and $400 \mathrm{~m} / \mathrm{s}$.

\section{Numerical Simulations}

In this section, the penetration process of projectile penetration with the FC-RPC target was numerically simulated by
LS-DYNA codes, which can supply sufficient data for the analysis of the antipenetration performance of the composite target. More importantly, one of the main purposes of this paper was to analyze the influence of the fiber layer on the results of the penetration calculation. The advantages of using numerical simulation to study the antipenetration physical properties of composite targets are reflected in the following analysis.

3.1. Numerical Model. Numerical models were generated using FE ANSYS software, while numerical calculations were performed with LS-DYNA codes, both commercially available. The numerical model for the projectile and targets had the same overall dimensions of the test specimen, but some details that do not affect the result of the calculation were corrected to obtain a better mesh. The thickness of the RPC target was modeled only $500 \mathrm{~mm}$ because it was enough to simulate a semi-infinite target with the nonreflective boundary used at the bottom of the RPC target. A quarter models of the target and projectile were established owing to the symmetry of the model to improve calculation efficiency, as shown in Figure 6. Each model was established using reduced integration solid elements defined by eight nodes having nine degrees of freedom (SOLID 164). To highlight the details of deformation and failure, the region directly under the projectile impact was modeled with relatively dense meshes. To balance numerical convergence and computational time, the minimum finite element size of the target was $1 / 25$ of the diameter of the projectile, which means 25 finite elements were divided within the radius range of the projectile. Mesh convergence analysis showed that further mesh refinement resulted in little improvement in the accuracy but a greater sacrifice of computational time.

As mentioned earlier, the large-sized FC targets were composed of numerous ceramic blocks and fiber layers, and the fiber layer has an important influence on the antipenetration performance of FC targets. It is the bonding of the fiber layer that keeps ceramic blocks in good integrity during the penetration process. Alternately, the fiber layer was not conducive to the erosion of the projectile. The fiber layer between the ceramic layers also changed the reflection and transmission characteristics of the stress wave at the interface between ceramic blocks. To analyze the influence of the fiber layer on the antipenetration performance of the FC target, three different modeling schemes were used to establish the finite element model of the FC target.

3.1.1. Separate Model of the FC Target. The first finite element model used a separate model. As shown in Figure 7, the ceramic block and the fiber layer were modeled, the size of the ceramic block was $100 \mathrm{~mm} \times 100 \mathrm{~mm} \times 20 \mathrm{~mm}$, and the thickness of the fiber layer was $2 \mathrm{~mm}$. Separate models treat ceramics and fibers as different finite elements, which can take into account the bond-slip relationship between ceramic and fiber finite elements. The ceramic layer was assembled by ceramic blocks, and the fiber layer was used to simulate the bonding relationship between the ceramic blocks, which were close to the composite of the real FC target. The automatic surface to surface contact in 
TABLE 2: Material parameters of ceramic and fiber.

\begin{tabular}{lccccc}
\hline Material & Density $\left(\mathrm{kg} / \mathrm{m}^{3}\right)$ & Elasticity modulus $(\mathrm{GPa})$ & Bending strength $(\mathrm{MPa})$ & Hardness $(\mathrm{HB})$ & Fracture toughness $\left(\mathrm{MN} / \mathrm{m}^{3 / 2}\right)$ \\
\hline Ceramic & 3650 & 381 & 439 & 1500 & 4.81 \\
Fiber & 2600 & 70 & 2400 & - & - \\
\hline
\end{tabular}

TABLE 3: Material parameters of RPC.

\begin{tabular}{lcccc}
\hline Density $\left(\mathrm{kg} / \mathrm{m}^{3}\right)$ & Elasticity modulus $(\mathrm{GPa})$ & Compressive strength $(\mathrm{MPa})$ & Shear strength $(\mathrm{MPa})$ & Fracture toughness $\left(\mathrm{MN} / \mathrm{m}^{3 / 2}\right)$ \\
\hline 2850 & 38 & 176 & 8.2 & 11.6 \\
\hline
\end{tabular}

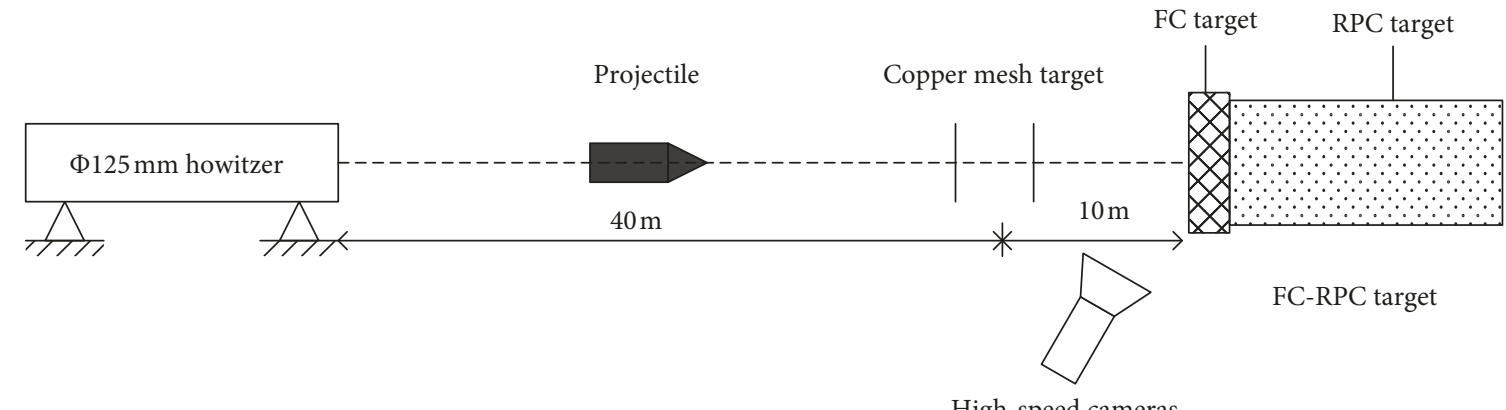

FIGURE 5: Arrangement diagram of the test.

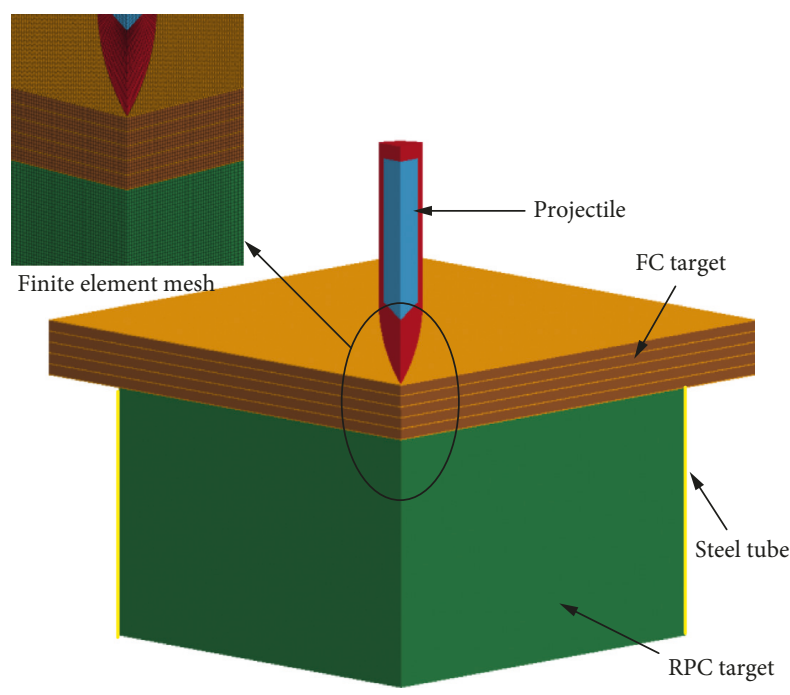

FIGURE 6: Numerical model of the target.

the LS-DYNA program was used to simulate the bond-slip relationship between the ceramic and fiber layers.

3.1.2. Combined Model of the FC Target. The second finite element model used a combined model. As shown in Figure 8 , the ceramic layer was considered as a homogeneous medium for overall modeling per $20 \mathrm{~mm}$ of thickness. The thickness of the fiber layer was $2 \mathrm{~mm}$. This modeling approach simplifies the interaction between the ceramic blocks of the ceramic layer. Because the wave resistance and other mechanical properties of the ceramic block were the same, the stress wave propagated between each ceramic block as in a uniform medium, and no reflection occurred. This

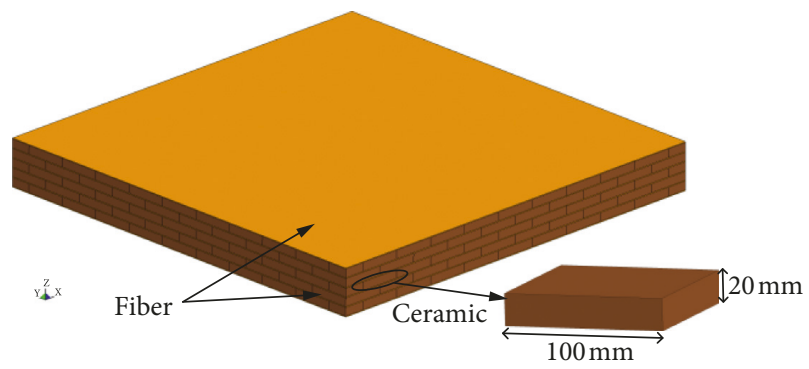

FIgURE 7: Separate model of the FC target.

simplified model could improve the calculation efficiency. To analyze the effects of the fiber layer, a layered model comprising a fiber layer and no fiber layer will be compared.

3.1.3. Integral Model of the FC Target. To further improve the computational efficiency, the third finite element model used the integral modeling scheme. The FC target composed of ceramic blocks and fiber layers was modeled as a uniform continuous medium, as shown in Figure 9. In this model, the FC target was considered as a mixture of fiber and ceramic, and the integral model could effectively improve the modeling and calculation efficiency of the finite element model. In fact, this model could also consider the effects of fiber action but requires more mechanical property testing to input material parameters into the constitutive model.

All finite element models used in this paper are listed in Table 4. Models A, B, and C correspond to the separated model, combined model, and integral model described above, respectively. Models B1 and B2 both used a combined model, but Model B2 does not contain a fiber layer. The modeling approach and the effect of the fiber layer on the 


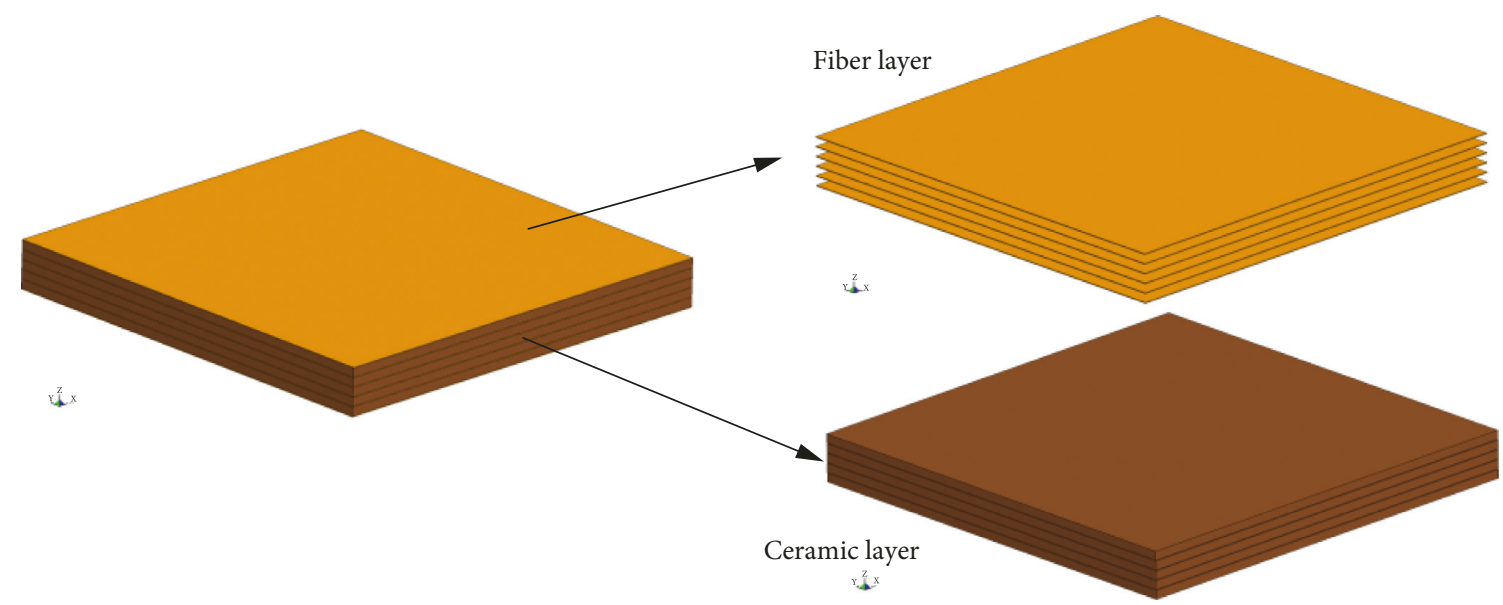

Figure 8: Combined model of the FC target.

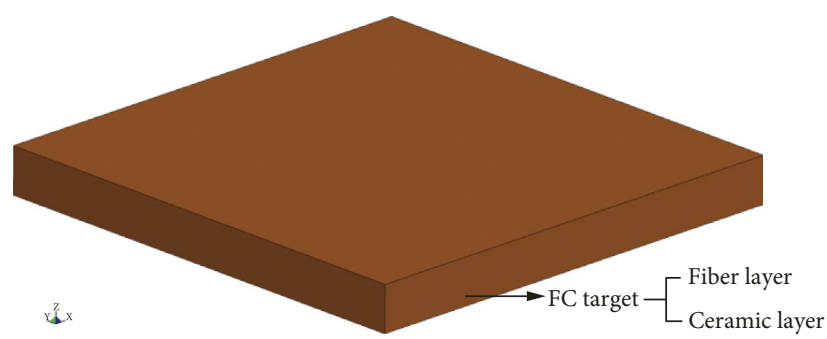

FIgURE 9: Integral model of the FC target.

TABLE 4: Various finite element model for FC targets.

\begin{tabular}{lcccc}
\hline NO. & Model name & Model style & Interfaces between ceramic blocks & Interfaces between ceramic layers \\
\hline 1 & Model A & Separate model & Automatic surface to surface contact & Considered by the fiber layer \\
2 & Model B1 & Combined model & Considered by the common node & Considered by the fiber layer \\
3 & Model B2 & Combined model & Considered by the common node & Automatic surface to surface contact \\
4 & Model C & Integral model & Considered by the common node & Considered by the common node \\
\hline
\end{tabular}

results of the penetration calculation will be discussed in detail in the following section.

\subsection{Material Model}

3.2.1. Projectile and Fiber. The MAT _PLASTICITY_ KINEMATIC material model (MAT\#003) [13] was used to model the behavior of the projectile because only slight deformation occurred from the test results. The model for the yield stress, $\sigma_{\mathrm{y}}$, is expressed as

$$
\sigma_{\mathrm{y}}=\left(1+\left(\frac{\dot{\varepsilon}}{C}\right)^{1 / P}\right)\left(\sigma_{0}+\beta E_{\mathrm{p}} \varepsilon_{\mathrm{p}}^{\text {eff }}\right),
$$

where $\dot{\varepsilon}$ is the strain rate; $\sigma_{0}$ is the initial yield stress; $C$ and $P$ are the strain rate parameters; $\varepsilon_{\mathrm{p}}^{\text {eff }}$ is the equivalent plastic strain; $\beta$ is the hardening parameter, $0<\beta<1$; and $E_{\mathrm{p}}$ is the plastic hardening modulus, expressed as

$$
E_{\mathrm{p}}=\frac{E_{\mathrm{tan}} E}{E-E_{\tan }}
$$

where $E$ is the elastic modulus and $E_{\tan }$ is the tangent modulus.

The parameters of materials for the projectile used in the numerical simulation are shown in Table 4 . To make the mass of the projectile $25.88 \mathrm{~kg}$, the core part used an elasticplastic material model with a density of $2.12 \mathrm{~g} / \mathrm{cm}^{3}$, and the yield strength was $255 \mathrm{MPa}$.

The main role of the fiber layer in the antipenetration process of the target was to maintain good integrity of the FC target. Therefore, to simplify the complexity of the problem, the fiber material also used the MAT_PLASTICITY_KINEMATIC material model, and its mechanical properties are shown in Table 5.

3.2.2. RPC. HJC constitutive model presented by Holmquist et al. [14] is suitable for normal concrete subjected to large strain, high strain rate, and high pressure, which were proved to be also suitable for RPC [12]. The HJC model is summarized in Figure 10, which consists of strength, pressure, and damage. 
TABLE 5: Material parameters for the projectile and fiber.

\begin{tabular}{lcccccccc}
\hline Material & $\mathrm{P}\left(\mathrm{g} \cdot \mathrm{cm}^{-3}\right)$ & $E(\mathrm{GPa})$ & $v$ & $\sigma_{\mathrm{y}}(\mathrm{MPa})$ & $\sigma_{\mathrm{b}}(\mathrm{MPa})$ & $C$ & $P$ & $\varepsilon_{\mathrm{f}}$ \\
\hline Projectile & 7.83 & 206 & 0.29 & 1280 & 1620 & 40.4 & 5 \\
Fiber & 2.60 & 70 & 0.20 & 2400 & - & - & - & 0.02 \\
\hline
\end{tabular}

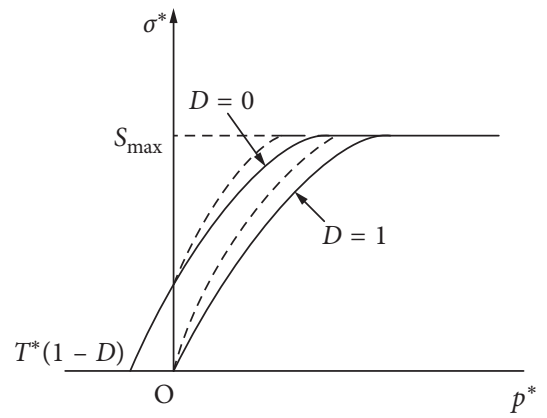

(a)

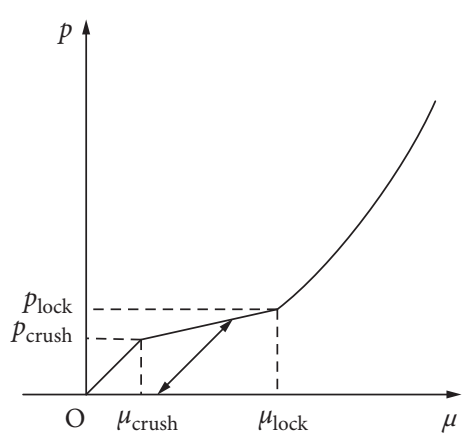

(b)

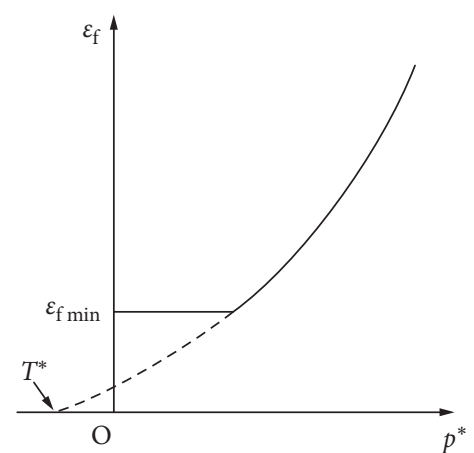

(c)

FIgURE 10: Description of the HJC model: (a) strength; (b) pressure; (c) damage.

The HJC model defines the normalized equivalent stress as

$$
\sigma^{*}=\left[A(1-D)+B P^{* N}\right]\left(1+C \ln \dot{\varepsilon}^{*}\right),
$$

where $D$ is the damage; $P^{*}=P / f_{c}$ is the normalized pressure, in which $P$ and $f_{\mathrm{c}}$ are the actual pressure and strength, respectively; $\dot{\varepsilon}^{*}$ is the normalized plastic strain rate for $\dot{\varepsilon}_{0}=1.0 \mathrm{~s}^{-1}$; and $A, B, C$, and $N$ are the normalized cohesive strength, normalized pressure hardening coefficient, pressure hardening exponent, and strain rate coefficient, respectively.

The fractural damage for fracture is accumulated in a manner similar to that used in the Johnson-Cook fracture model [16]. The failure criteria are based on damage evolution, where the damage parameter $D$ of a material element is defined as

$$
D=\frac{\sum \Delta \varepsilon}{\sum \varepsilon_{\mathrm{f}}}
$$

where $\Delta \varepsilon$ is the increment of the equivalent plastic strain in a cyclic integral and $\varepsilon_{\mathrm{f}}$ is the equivalent failure strain, expressed as

$$
\varepsilon_{\mathrm{f}}=D_{1}\left(P^{*}+T^{*}\right)^{D_{2}},
$$

where $T^{*}=T / f_{\mathrm{c}}$ is the normalized maximum tensile hydrostatic pressure, in which $T$ is the maximum tensile hydrostatic pressure the material can withstand, and $D_{1}$ and $D_{2}$ are material constants.

The hydrostatic pressure-volume response is separated into three response regions. The first region is linear elastic:

$$
P=K_{\mathrm{e}} \mu, \quad P \leq P_{\text {crush }},
$$

where $K_{\mathrm{e}}$ is the elastic bulk module, $\mu=\rho / \rho_{0}-1$ for current density and initial density, and $P_{\text {crush }}$ is the pressure at the crush state.
The second region is referred to as the transition region occurring at $P_{\text {crush }} \leq P \leq P_{\text {lock}}$, and the relationship is expressed as

$$
P= \begin{cases}P_{\text {crush }}+K_{\mathrm{t}}\left(\mu-\mu_{\text {crush }}\right), & \text { loading, } \\ P_{\max }+\left[(1-F) K_{\mathrm{t}}+F K_{1}\right]\left(\mu-\mu_{\max }\right), & \text { unloading, }\end{cases}
$$

where $K_{\mathrm{t}}$ is the bulk module under the transition region; $P_{\max }$ and $\mu_{\max }$ are the maximum pressure and volumetric strain before unloading, respectively; $\mu_{\text {crush }}$ is the volumetric strain at the crush state; and $F=\left(\mu_{\max }-\mu_{\text {crush }}\right) /\left(\mu_{\text {plock }}-\mu_{\text {crush }}\right)$ is the compression factor.

The third region defines the relationship for the fully dense material, expressed as

$$
P= \begin{cases}K_{1} \bar{\mu}+K_{2} \bar{\mu}^{2}+K_{3} \bar{\mu}^{3}, & \text { loading, } \\ K_{1} \bar{\mu}, & \text { unloading, }\end{cases}
$$

where $\bar{\mu}=\left(\mu-\mu_{\text {lock }}\right) /\left(1+\mu_{\text {lock }}\right)$ is used, so that the constants $\left(K_{1}, K_{2}\right.$, and $\left.K_{3}\right)$ are equivalent to those used for material with no voids, respectively. $\mu_{\text {lock }}=\rho_{\text {grain }} / \rho_{0}-1$ is the locking volumetric strain, where $\rho_{\text {grain }}$ is the grain density.

As mentioned earlier, the axial quasi-static compressive strength of the present RPC was measured to be $176 \mathrm{MPa}$, which is similar to that reported by Tai [12]. Consequently, the material parameters of RPC used in this study are taken from [12], as summarized in Table 6. The parameters of normal concrete are shown in Table 7, which would be used in the numerical simulation below.

3.2.3. Ceramic. Another constitutive models for brittle materials presented by Johnson and Holmquist is JH2 [17], which is more recently developed for the ceramic material. Figure 11 presents the model characterized for the ceramic material. There are three main improvements of the model [17]. (1) The 
TABLE 6: HJC material model parameters for RPC [12].

\begin{tabular}{lccccccccccccccc}
\hline$\rho\left(\mathrm{g} \cdot \mathrm{cm}^{-3}\right)$ & $G(\mathrm{GPa})$ & $S_{\mathrm{MAXR}}$ & $f_{\mathrm{c}}(\mathrm{MPa})$ & EFMIN & $A$ & $B$ & $C$ & $N$ & $f_{\mathrm{t}}(\mathrm{MPa})$ & $K_{1}(\mathrm{MPa})$ & $K_{2}(\mathrm{MPa})$ & $K_{3}(\mathrm{MPa})$ & $D_{1}$ & $D_{2}$ \\
\hline 2.85 & 22.8 & 3.5 & 176 & 0.01 & 0.79 & 1.35 & 0.007 & 0.4 & 13.8 & 85 & -171 & 208 & 0.78 & 1 \\
\hline
\end{tabular}

TABLE 7: HJC material model parameters for normal concrete [14].

\begin{tabular}{lccccccccccccccc}
\hline$\rho\left(\mathrm{g} \cdot \mathrm{cm}^{-3}\right)$ & $G(\mathrm{GPa})$ & $S_{\text {MAXR }}$ & $f_{\mathrm{c}}(\mathrm{MPa})$ & EFMIN & $A$ & $B$ & $C$ & $N$ & $f_{\mathrm{t}}(\mathrm{MPa})$ & $K_{1}(\mathrm{MPa})$ & $K_{2}(\mathrm{MPa})$ & $K_{3}(\mathrm{MPa})$ & $D_{1}$ & $D_{2}$ \\
\hline 2.44 & 14.86 & 7 & 48 & 0.01 & 0.79 & 1.6 & 0.007 & 0.61 & 4.0 & 85 & -171 & 208 & 0.04 & 1 \\
\hline
\end{tabular}

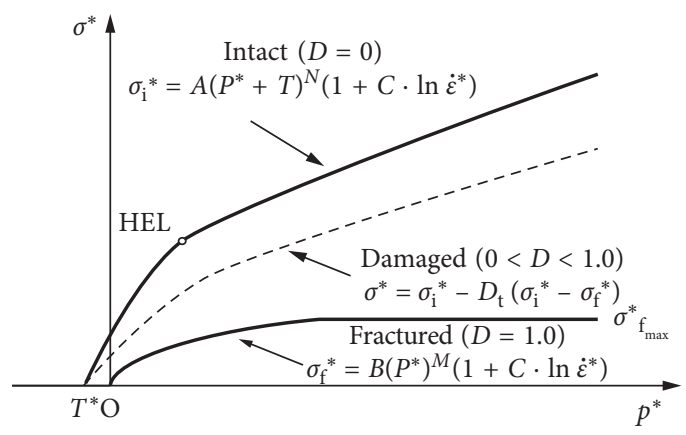

(a)

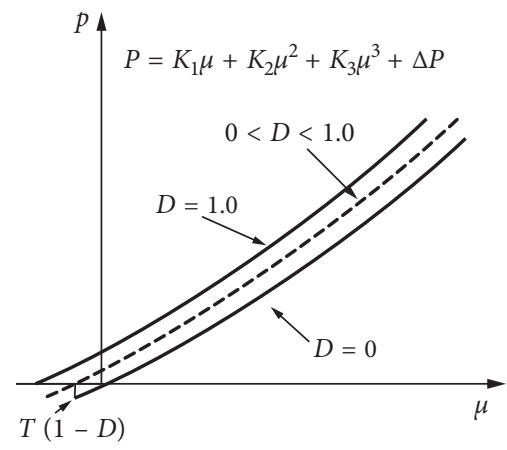

(b)

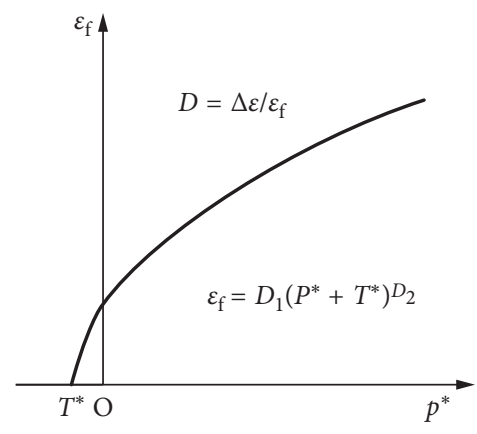

(c)

Figure 11: Description of the JH2 model: (a) strength; (b) pressure; (c) damage.

model begins to soften when the damage begins to accumulate. This allows for gradual softening of the material under increasing plastic strain. (2) The strength and pressure are normalized by the strength and pressure components of the Hugoniot elastic limit (HEL), which allows for many of the constant to be dimensionless. (3) The strength and damage are analytic functions of the pressure and other variables. The strength generally is a smoothly varying function of the intact strength, fracture strength, strain rate, and damage.

The normalized equivalent stress is

$$
\sigma^{*}=(1-D) \sigma_{1}^{*}+D \sigma_{\mathrm{f}}^{*}
$$

where $\sigma_{1}^{*}$ is the normalized intact equivalent stress and damage, $\sigma_{\mathrm{f}}^{*}$ is the normalized fracture stress, and $D$ is the damage $(0 \leq D \leq 1.0)$.

The normalized equivalent stresses have the following general form:

$$
\sigma^{*}=\frac{\sigma}{\sigma_{\mathrm{HEL}}}
$$

where $\sigma_{1}^{*}$ is the actual equivalent stress and $\sigma_{\mathrm{HEL}}$ is the equivalent stress at the HEL.

The normalized intact strength is given by

$$
\sigma_{1}^{*}=A\left(P^{*}+T^{*}\right)^{N}\left(1+C \cdot \ln \dot{\varepsilon}^{*}\right)
$$

and the normalized fracture strength is given by

$$
\sigma_{\mathrm{f}}^{*}=B\left(P^{*}\right)^{M}\left(1+C \cdot \ln \dot{\varepsilon}^{*}\right)
$$

where $A, B, C, M$, and $N$ are material constants. The normalized pressure is $P^{*}=P / P_{\mathrm{HEL}}$, where $P$ is the actual pressure and $P_{\mathrm{HEL}}$ is the pressure at the HEL. The normalized maximum tensile hydrostatic pressure is $T^{*}=T / T_{\mathrm{HEL}}$, where $T$ is the maximum tensile hydrostatic pressure the material can withstand and $T_{\text {HEL }}$ is the tensile hydrostatic pressure at the HEL and $\varepsilon^{*}$ is the normalized plastic strain rate for $\varepsilon_{0}=1.0 \mathrm{~s}^{-1}$.

The damage for fracture is accumulated in a manner similar to that used in the HJC model and the Johnson-Cook fracture model.

The hydrostatic pressure before fracture begins is simply as follows:

$$
P= \begin{cases}K_{1} \mu+K_{2} \mu^{2}+K_{3} \mu^{3}, & \mu \geq 0 \\ K_{1} \mu, & \mu<0\end{cases}
$$

where $K_{1}, K_{2}$, and $K_{3}$ are material constants and $\mu=\rho / \rho_{0}-1$ for current density and initial density.

Parameters of ceramic materials used in numerical simulation are shown in Table 8 .

\section{Results}

\subsection{Test Results}

4.1.1. Damage of Projectiles. Figure 12 shows the damaged projectiles after penetrating the FC-RPC targets. It can be seen from Figure 12(a) that the projectile remains intact after penetration, but blunting occurs on the projectile head with obvious signs of erosion (Figure 12(b)). The results of blunting on the projectile head showed that the FC target had a certain erosion effect on the projectile. Experiments [18] claimed that the projectile can be seen as a rigid body when penetrating reinforced concrete at low speed $(350-400 \mathrm{~m} / \mathrm{s})$ because of the slight damage and 
TABLE 8: JH2 material model parameters for ceramic [15].

\begin{tabular}{lcccccccccccccccc}
\hline$\rho /\left(\mathrm{g} \cdot \mathrm{cm}^{-3}\right)$ & $\begin{array}{c}G \\
(\mathrm{GPa})\end{array}$ & $A$ & $B$ & $C$ & $M$ & $N$ & $\mathrm{EPS} 0$ & $\begin{array}{c}T \\
(\mathrm{GPa})\end{array}$ & SFMAX & $\begin{array}{c}\sigma_{\mathrm{HEL}} \\
(\mathrm{GPa})\end{array}$ & $\begin{array}{c}P_{\mathrm{HEL}} \\
(\mathrm{GPa})\end{array}$ & $D_{1}$ & $D_{2}$ & $\begin{array}{c}K_{1} \\
(\mathrm{GPa})\end{array}$ & $\begin{array}{c}K_{2} \\
(\mathrm{GPa})\end{array}$ & $\begin{array}{c}K_{3} \\
(\mathrm{GPa})\end{array}$ \\
\hline 3.65 & 109.7 & 0.88 & 0.28 & 0.007 & 0.6 & 0.64 & 1 & 0.262 & 1 & 5.3 & 2.8 & 0.02 & 0.83 & 228.6 & 191.4 & 111.5 \\
\hline
\end{tabular}

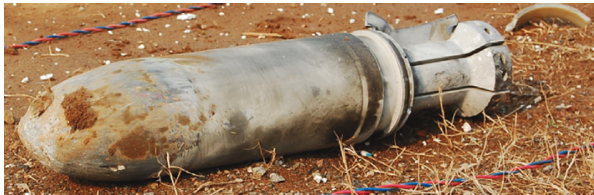

(a)

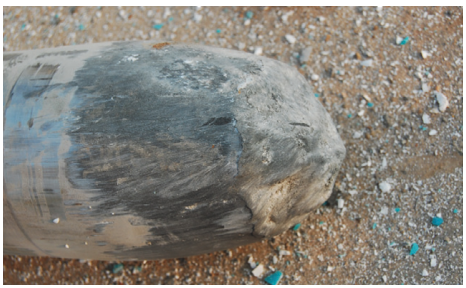

(b)

FIGURE 12: Damaged projectiles after penetrating: (a) projectile overall form after testing; (b) erosion of the projectile head after testing.

deformation. In this paper, due to the high hardness and high strength of ceramics, the projectile heads were obviously passivated, resulting in a significant decrease in projectile penetration efficiency, indicating that the FC-PRC targets have high antipenetration performance.

4.1.2. Damage of Targets. The test results are summarized in Table 8 . The penetration test utilized a total of 3 guns, the velocity of projectiles ranged from $360 \mathrm{~m} / \mathrm{s}$ to $400 \mathrm{~m} / \mathrm{s}$, within the expected speed range, and the average velocity of the projectiles can be considered as $375 \mathrm{~m} / \mathrm{s}$. The variable in the test was the thickness of the FC targets, and the difference in velocity $(8.7 \%)$ was due to the test error, which is acceptable in the large-diameter projectile penetration test. From Table 9, it can be found that all of the FC targets were perforated, and the DOP of RPC targets were decreased with the thickness of FC targets.

Figure 13 shows the damage of the no. 1 target when the impact velocity is $397 \mathrm{~m} / \mathrm{s}$. The FC target received serious damage around the impact point, some of the ceramic blocks sprayed out, and the target was perforated. The destruction of the FC target had typical ductile failure characteristics rather than the brittle failure of individual ceramic blocks. It was indicated that the restraint effect of the fiber was obvious. The front face of the RPC target formed a $100 \mathrm{~mm}$ in diameter and $28 \mathrm{~mm}$ in penetration depth crater.

As shown in Figure 14, the no. 2 target also received serious local damage at an impact velocity of $369 \mathrm{~m} / \mathrm{s}$. The FC target crushed locally at the impact point, and the amount of ceramic blocks sprayed out was more than that of no.1 target. The projectile perforated the $100 \mathrm{~mm}$ thick FC target and penetrated into the RPC target $108 \mathrm{~mm}$ in depth, forming a $360 \mathrm{~mm}$ diameter of cavity destruction.
TABLE 9: Experimental results.

\begin{tabular}{cccccc}
\hline No. $\begin{array}{c}\text { Impact } \\
\text { velocity } \\
(\mathrm{m} / \mathrm{s})\end{array}$ & $\begin{array}{c}\text { Total thickness } \\
\text { of the ceramic } \\
\text { block }(\mathrm{mm})\end{array}$ & $\begin{array}{c}\text { Thickness } \\
\text { of FC } \\
\text { targets } \\
(\mathrm{mm})\end{array}$ & $\begin{array}{c}\text { DOP } \\
(\mathrm{mm})\end{array}$ & $\begin{array}{c}\text { Crater } \\
\text { diameter of } \\
\text { RPC (mm) }\end{array}$ \\
\hline 1 & 397 & 160 & 178 & 28 & 100 \\
2 & 369 & 100 & 112 & 106 & 360 \\
3 & 365 & 60 & 68 & 164 & 460 \\
\hline
\end{tabular}

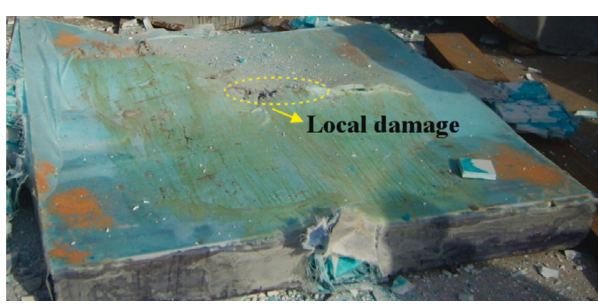

(a)

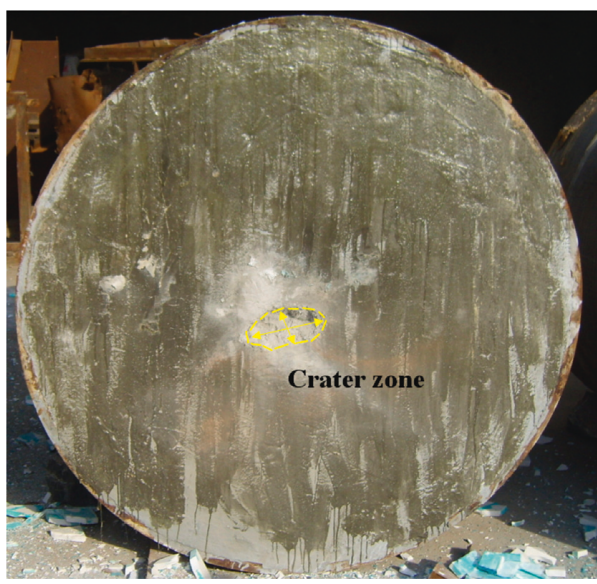

(b)

FIGURE 13: Damage results of FC-RPC target 1: (a) damage of the FC target; (b) damage of the RPC target.

Figure 15 shows the damage of the no. 3 target at an impact velocity of $365 \mathrm{~m} / \mathrm{s}$. The failure model of the FC target was similar to that of the no. 2 target. The amount of ceramic sprayed out was greatly increased from that of the no. 1 and no. 2 targets. As shown in Figure 15, a $460 \mathrm{~mm}$ in diameter and $164 \mathrm{~mm}$ in depth penetration crater was formed at the front face of the RPC target, which was more serious than target no. 1 and no. 2 .

\subsection{Numerical Simulation Results}

4.2.1. Validations of Three Numerical Models. The numerical simulation results for depth of penetration are summarized in Table 10. It can be found that the numerical simulation 


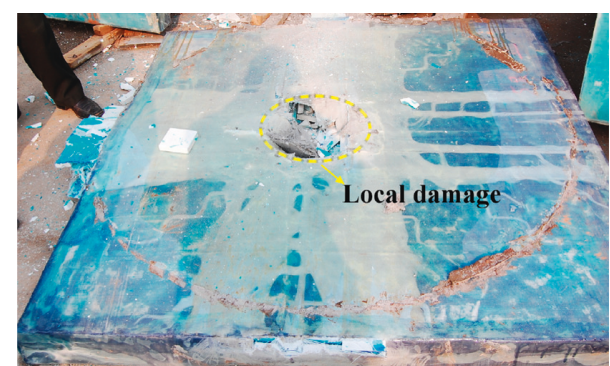

(a)

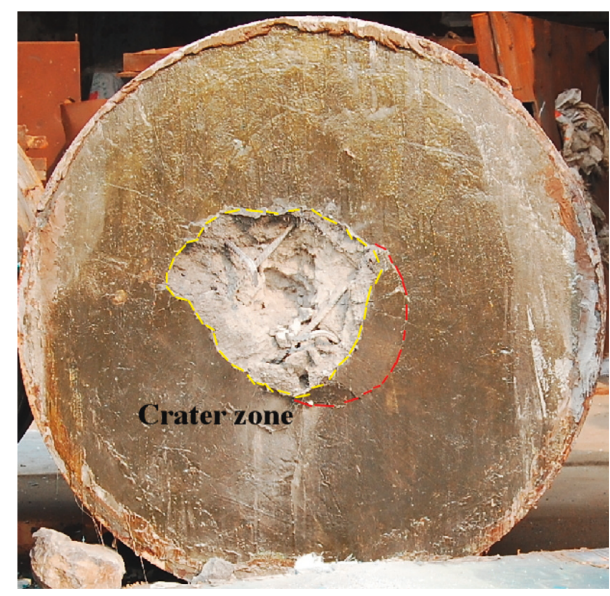

(b)

Figure 14: Damage results of FC-RPC target 2: (a) damage of the FC target; (b) damage of the RPC target.

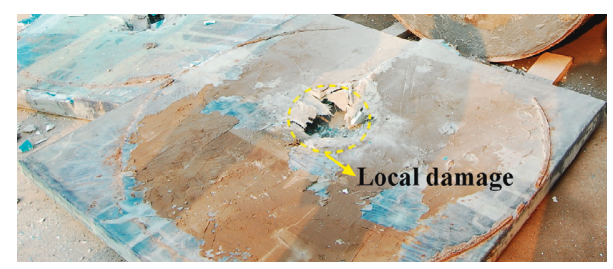

(a)

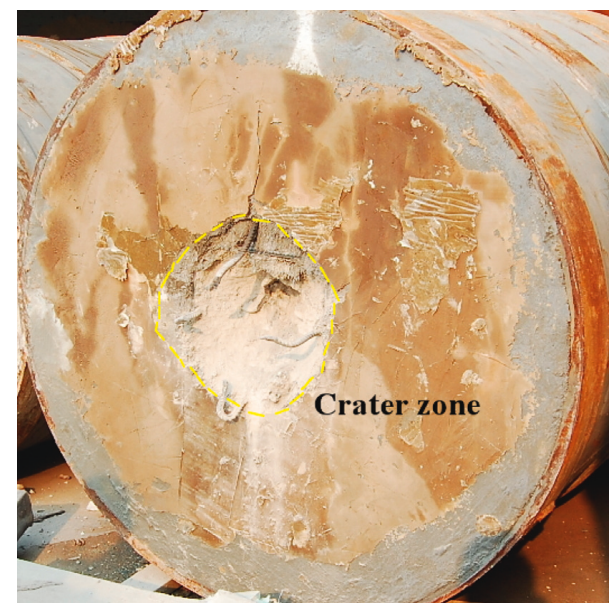

(b)

FIGURE 15: Damage results of FC-RPC target 3: (a) damage of the FC target; (b) damage of the RPC target. results of Model B were in good agreement with the results obtained in the test, the relative error of the depth of penetration was within $10 \%$, and the rationalities of the material constitutive model, boundary condition, and contact were validated. The calculation results of Models B1 and B2 were very close, and the relative errors were within $5 \%$, indicating that modeling scheme B can better simulate the antipenetration performance of the composite target. All calculation results of Model A were larger than the experimental values and the results of other models, and the relative error with the experimental value were approximately $10 \%$. Although Model A was more elaborate, the automatic surface to surface contact between ceramic blocks used in model A did not reflect the bond-slip relationship, which was the main reason for the large prediction results. All calculation results of Model $\mathrm{C}$ were smaller than the experimental values and the results of other models. The numerical simulation results show that the integral model would overestimate the antipenetration ability of the FCRPC target, while the separate model would underestimate the antipenetration ability of the FC-RPC target. Therefore, a combined model would be used in subsequent simulations of this paper. Figure 16 also shows the comparison of all calculation results. The total penetration depth decreases as the thickness of the FC target increases.

4.2.2. Damage of Projectile and Targets. Figure 17 presents the damage of projectiles after penetration by numerical simulation using Model B1. The damage was mainly located on the head of the projectile, with less damage elsewhere, which agrees with the test results in Figure 12. The elements in the head of the projectiles were deleted because of large finite element deformation. Comparing Figures 17(a)-17(c), it can be found that the abrasion of the head of the projectile becomes more serious as the thickness of the ceramic target increases.

Figure 18 shows the damage of the FC-RPC target 2 with different numerical models. The damage areas were mainly distributed in the range of 2 times the diameter of projectiles. There were significant discrepancies in the crater diameter of targets under penetration. Both the HJC model and the JH2 model in LS-Dyna code delete an element by defining an equivalent plastic strain failure criterion, when the equivalent plastic strain of an element in a ceramic target or RPC target exceeds the damage threshold, the associated element is deleted. In particular, Model A simulates the throwing phenomenon of ceramic blocks by a separate model, as shown in Figure 18(a). It can be seen from Figure 18(b) that the ceramic and fiber layers were separated, which was the result of the tensile stress wave propagating at the interface between the ceramic and the fiber layer. The FC target of Model A (Figure 18(a)) and Model B1 (Figure 18(b)) fails in a ductile manner, which were in good agreement with the experimental results in Figure 14. Separation also occurred between the layers of the Model B2 (Figure 18(c)), but there was no throwing on the upper surface of the FC target because no fiber layer was established. As shown in Figure 18(d), the plastic strain range of the target in Model C 
TABLE 10: Depth of penetration results of numerical simulation and experiments.

\begin{tabular}{cccccccccc}
\hline No. & $\begin{array}{c}\text { Results of the } \\
\text { experiment (mm) }\end{array}$ & $\begin{array}{c}\text { Results of Model A } \\
\text { Total depth } \\
(\mathrm{mm})\end{array}$ & $\begin{array}{c}\text { Relative } \\
\text { error }(\%)\end{array}$ & $\begin{array}{c}\text { Total depth of Model B1 } \\
(\mathrm{mm})\end{array}$ & $\begin{array}{c}\text { Results of Model B2 } \\
\text { error (\%) }\end{array}$ & $\begin{array}{c}\text { Total depth } \\
(\mathrm{mm})\end{array}$ & $\begin{array}{c}\text { Relative } \\
\text { error (\%) }\end{array}$ & Total depth (mm) & Relative error (\%) \\
\hline 1 & 188 & 206 & 9.57 & 204 & 8.51 & 200 & 6.38 & 160 & 14.89 \\
2 & 206 & 226 & 9.71 & 212 & 2.91 & 213 & 3.40 & 188 & 8.74 \\
3 & 224 & 250 & 11.61 & 242 & 8.04 & 238 & 6.25 & 203 & 9.38 \\
\hline
\end{tabular}

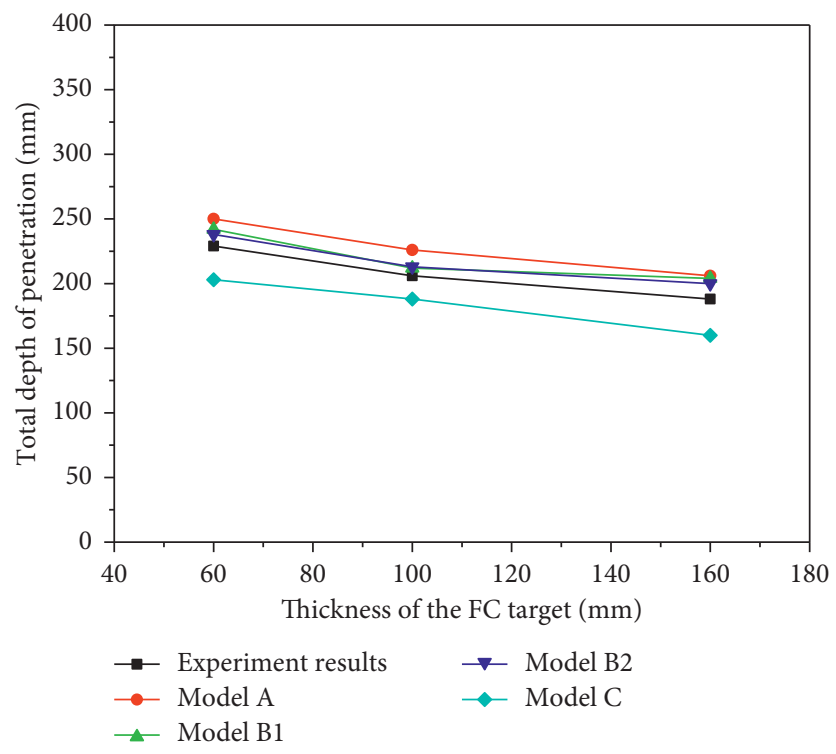

FIgURE 16: Depth of penetration results of numerical simulation and experiments.

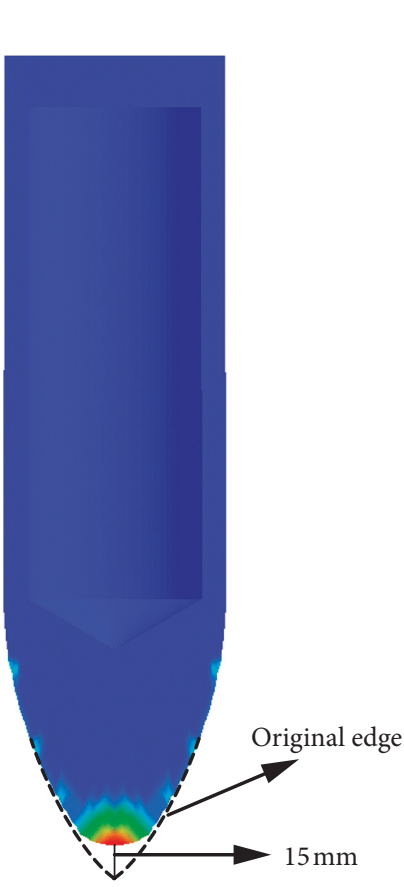

(a)

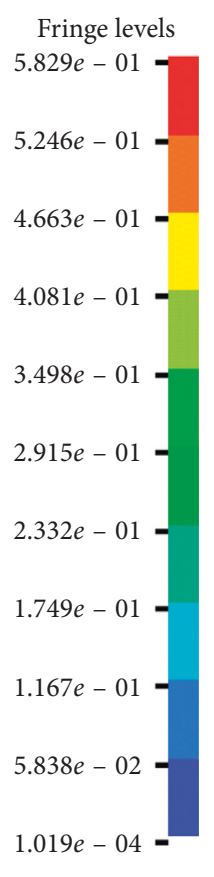

Figure 17: Continued.

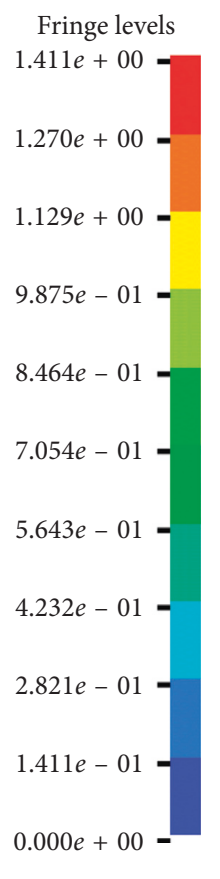

(b) 


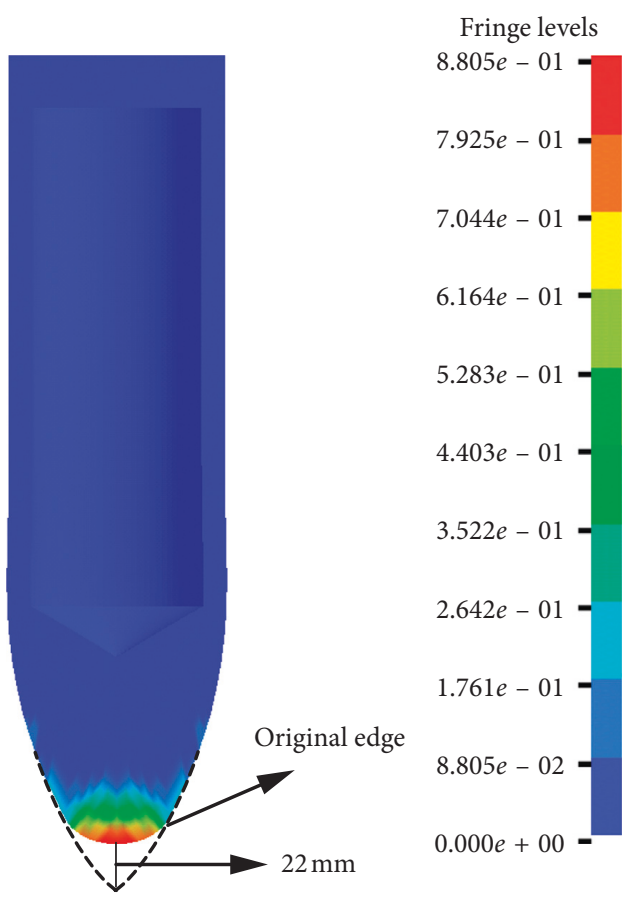

(c)

FIgURE 17: The damage of projectiles: (a) $60 \mathrm{~mm}$ FC target; (b) $100 \mathrm{~mm}$ FC target; (c) $160 \mathrm{~mm}$ FC target.

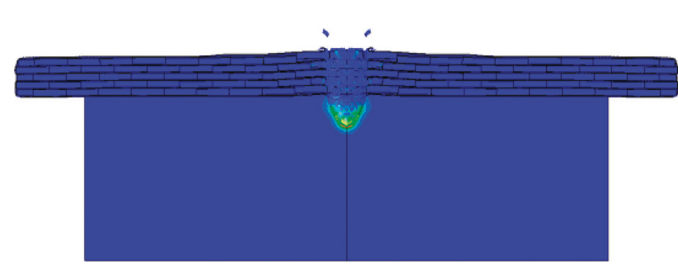

(a)

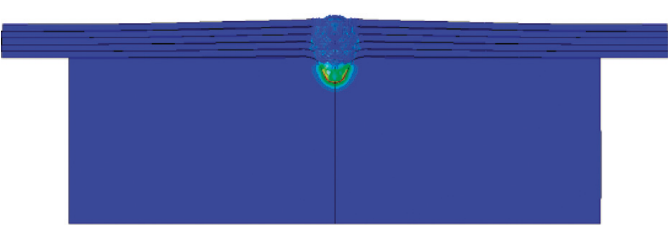

(c)

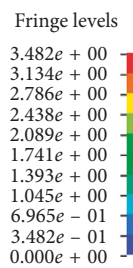

$0.000 e+00$

Fringe levels

$2.849 e+00$

$2.564 e+00$
$2.279 e+00$

$2.279 e+00$
$1.994 e+00$

$1.994 e+00$
$1.709 e+00$

$1.424 e+00$

$1.140 e+00$

$8.547 e-01$
$5.698 e-01$

$5.698 e-01$

$2.849 e-01$
$0.000 e+00$

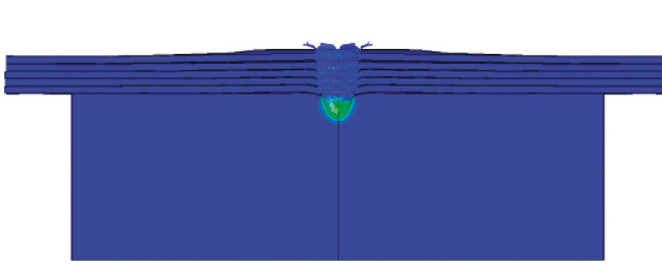

(b)

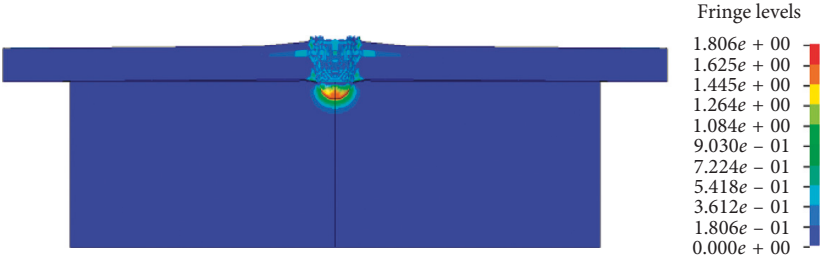

(d)
Fringe levels $3.035 e+00$ $2.732 e+00$
$2.428 e+00$ $2.428 e+00$ $1.821 e+00$ $1.518 e+00$ $214 e+00$ $9.106 e-0$ $6.071 e-01$ $3.035 e-0$ $0.000 e+00$

Fringe leve $806 e+00$ $.625 e+00$ $264 e+00$ $0.000 e+00$

FiguRE 18: Damage of FC-RPC target 2 by different models: (a) result of Model A; (b) result of Model B1; (c) result of Model B2; (d) result of Model C.

was greater than the calculation results of the other models. The FC target in Model C was a continuous homogeneous medium without gaps and fibrous layers, the stress wave will continuously propagate in the FC target, and so the damage range was larger.

Figure 19 shows the damage of the upper surface of the FC target 2. Figures 19(a)-19(c) correspond to the calculation results of Models A, B1, and B2, respectively, which were consistent with the experimental failure phenomenon in Figure 14(a). Both the HJC model and the JH2 model define the damage model by equivalent plastic strain, so the damage range obtained was slightly smaller than that of the test results (Figure 14(a)). As shown in Figure 19(d), in addition to the damage occurring near the impact point, significant damage occurred at the diagonal of the target. This phenomenon could be explained from the perspective of stress waves. The FC target in Model C was a continuous homogeneous medium without gaps and fibrous layers. When the compressive stress wave propagated toward the corner formed by the intersection of the two free surfaces, the tensile waves reflected by the two free surfaces will meet at the diagonal. Therefore, the damage distribution pattern 


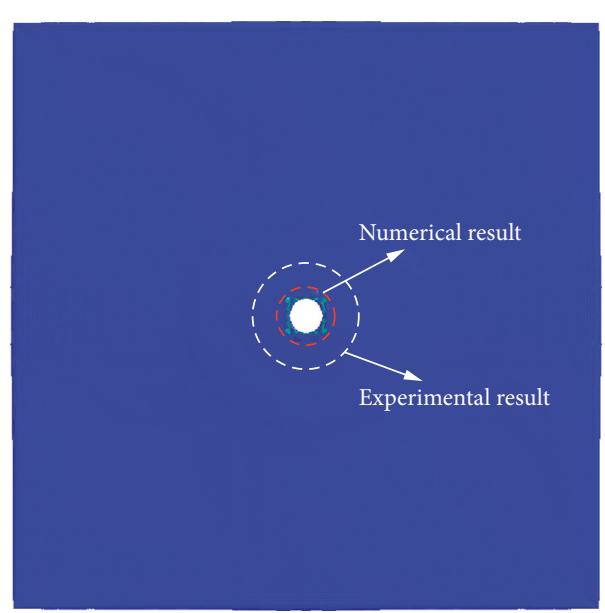

(a)

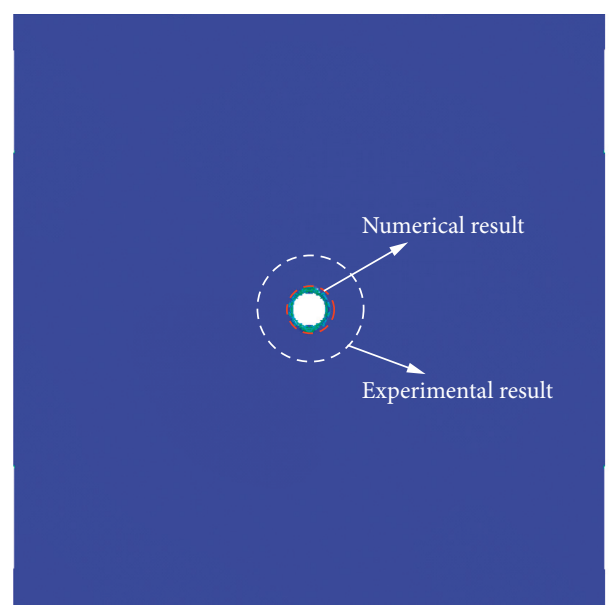

(c)

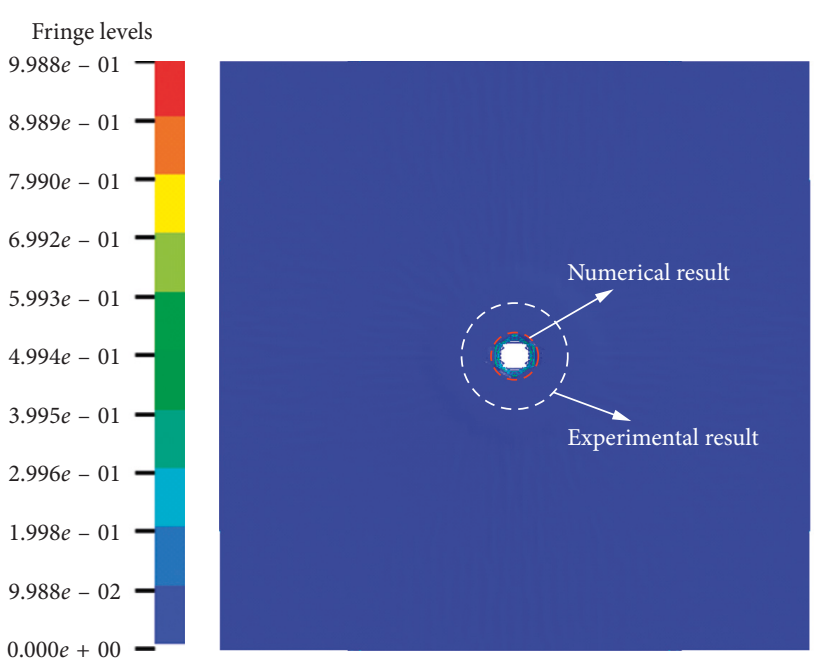

(b)
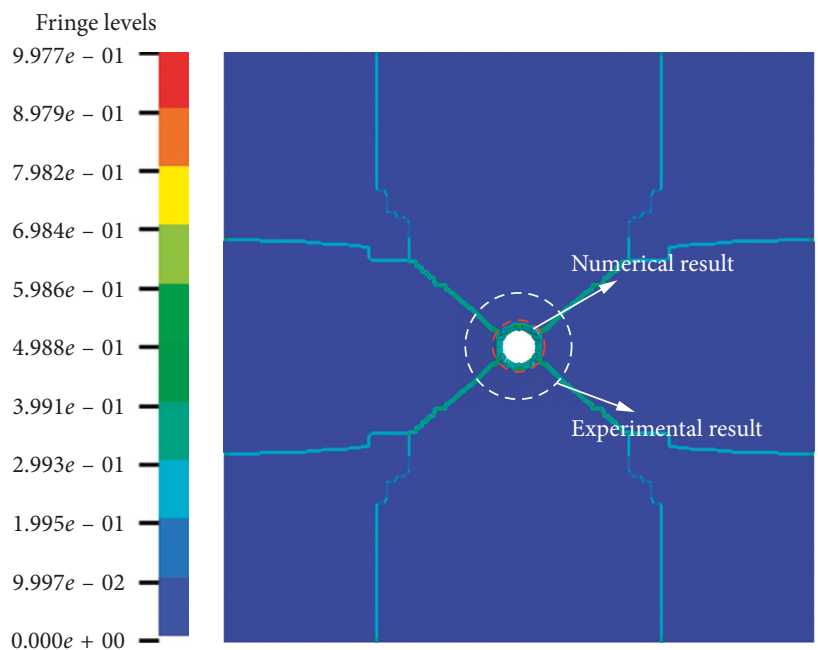

(d)

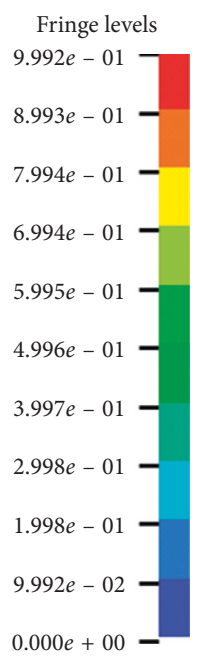

Fringe levels
$9.970 e-01-$
$8.973 e-01-$
$7.976 e-01-$
$6.979 e-01-$
$5.982 e-01-$
$4.985 e-01-$
$3.988 e-01-$
$2.991 e-01-$
$1.994 e-01-$
$9.970 e-02-$
$0.000 e+00-$

Figure 19: Damage of the FC-RPC target 2 by different models: (a) result of Model A; (b) result of Model B1; (c) result of Model B2; (d) result of Model C.

in Figure 19(d) was produced. However, the actual stress wave in the target would be changed by the propagation path due to the gap between the ceramic blocks and the existence of the fiber layer between the ceramic layers. Therefore, the calculation result of Model $\mathrm{C}$ did not reflect the damage distribution in the test.

4.2.3. Overload Characteristic Analysis. Figure 20 shows the comparison of the acceleration curves of the projectile penetrating the FC-RPC target. A $160 \mathrm{~mm}$ thick FC target was selected for acceleration curve comparison. Because the $160 \mathrm{~mm}$ thick FC target could make the projectile penetration process mainly in the FC target, it could better compare the influence of the FC modeling method on the acceleration curve. It can be seen from the figure that the overall change trend of the acceleration curves of Model A and Model B were consistent. The acceleration of Model C was greater than the accelerations in Model B and Model A because the ceramic material units in the model $\mathrm{C}$ were all conodes.

Figure 21 shows an acceleration curve comparison of different thicknesses of FC targets calculated by Model B1. As seen from the figure, the peak value of the acceleration curve increases as the thickness of the target increases. In the initial stage of penetration, the acceleration curve of the thicker target of the FC target rises slightly faster. The support stiffness obtained by the upper surface target during the initial stage of penetration increases as the thickness of the FC target increases, so that the acceleration of the projectile in the thicker target is greater in the initial stage of penetration. The acceleration curve in the $6 \mathrm{~mm}$ target rapidly drops after $0.5 \mathrm{~ms}$ due to the projectile penetration into the RPC target.

To compare the antipenetration performance of FC-RPC targets (16 mm thick FC target) with RPC targets and C40 concrete targets, numerical simulation of the projectile penetration into the RPC target and the C40 concrete target 


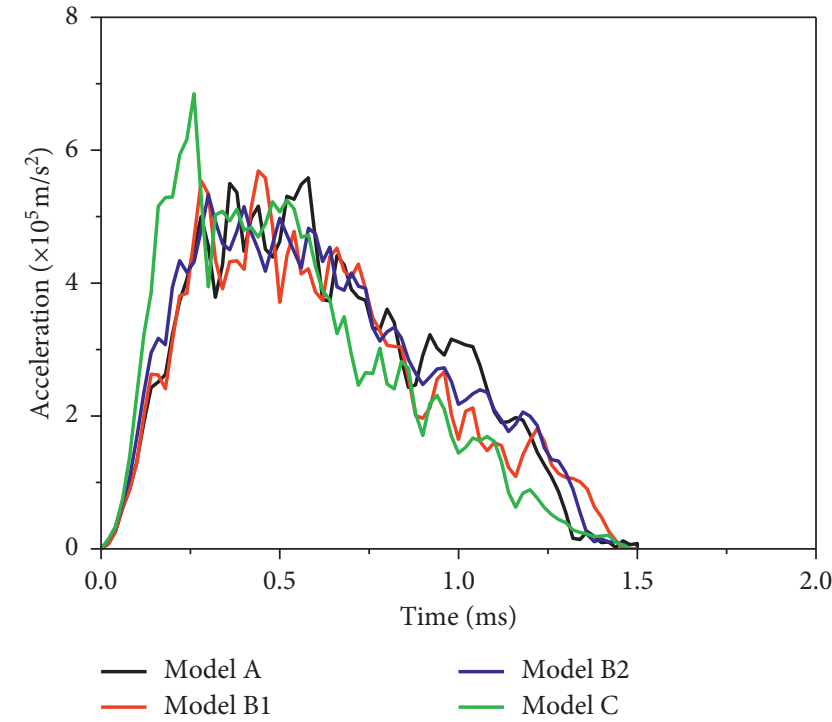

Figure 20: Acceleration curves of projectiles penetration FC-RPC target 3 .

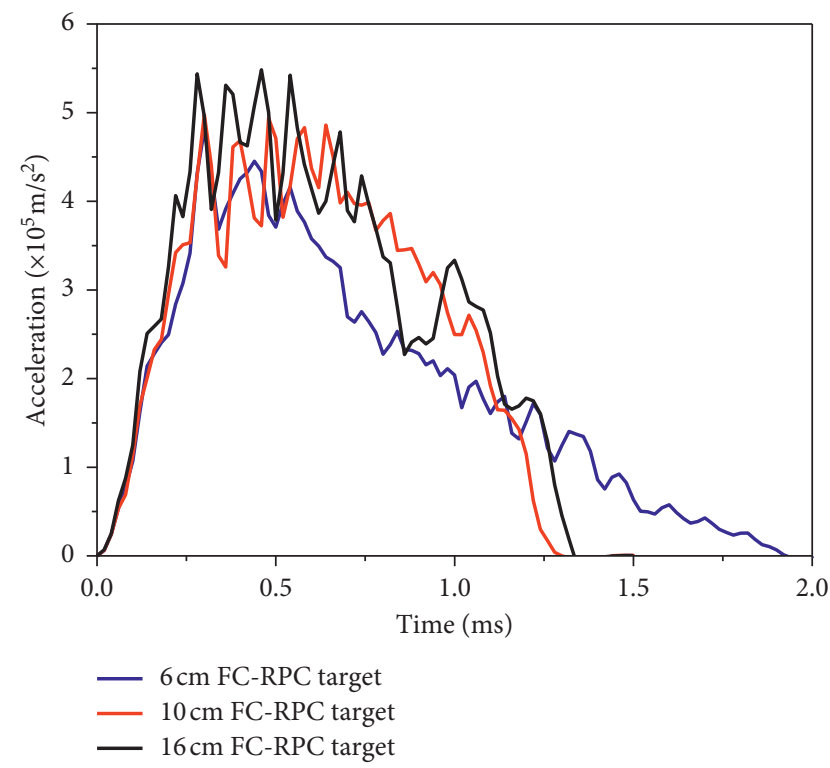

FIgURE 21: Acceleration time history curves of projectiles penetration FC-RPC targets.

was carried out. The dimensions of the projectile and the target are exactly the same as those in the test. To effectively simulate the semi-infinite target, a transmission boundary is applied at the bottom end of the target.

The acceleration time history curves of projectiles penetrating different targets are shown in Figure 22. The acceleration curve of C40 concrete presented a longer platform with a duration of $2.5 \mathrm{~ms}$. The acceleration curve of RPC first rose to a peak, and then slowly dropped to zero for a duration of $2.0 \mathrm{~ms}$. The trend of the acceleration curve of the FC-RPC target was obviously different from that of the $\mathrm{RPC}$ and $\mathrm{C} 40$ concrete targets. The curve rapidly rose to its peak in the early stage of penetration and then oscillated

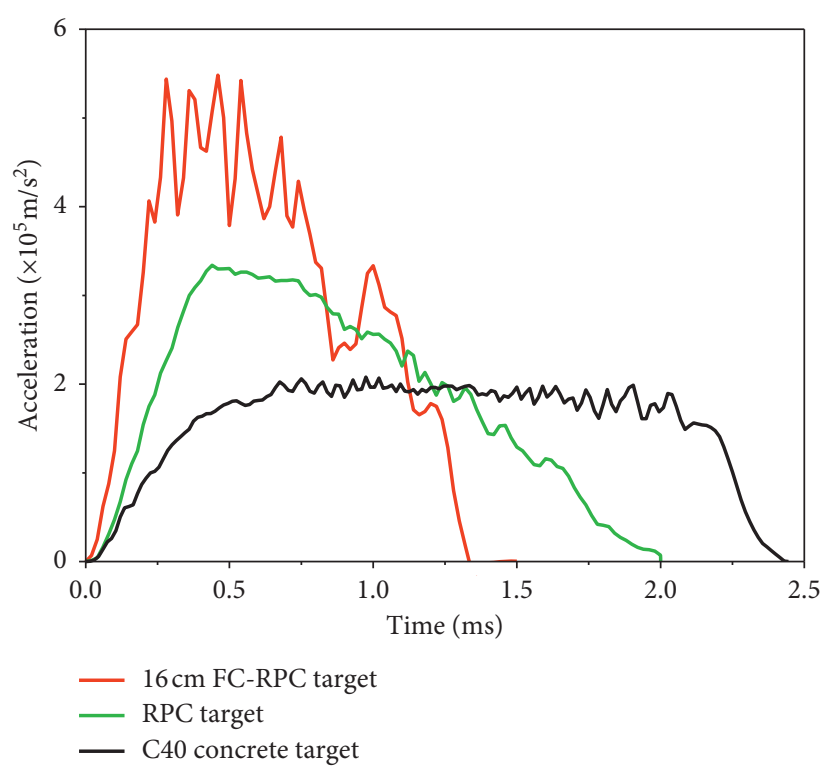

FIGURE 22: Acceleration time history curves of projectile penetration of different targets.

around a lower platform with a sustained distance of $1.3 \mathrm{~ms}$. The acceleration peak of the FC-RPC target was three times and two times as great as that of the C40 concrete target and RPC target, respectively. It is indicated that the antipenetration performance of the FC-RPC target is much higher than a normal concrete target.

All of the above test results and numerical simulation results demonstrate that the FC-RPC targets have excellent antipenetration performance. Quantitative analysis of the antipenetration performance of the FC target will be discussed in detail in the next section in conjunction with the results of the DOP test.

\section{DOP Analysis of Antipenetration Performance of FC-RPC Targets}

Because the ceramic material is mainly used in armor protection such as tank armor, its antiballistic performance is mainly evaluated by the mass efficiency factor and differential efficiency factor $[5,19]$, while concrete materials in engineering protection are mainly evaluated by their penetration coefficient or dimensionless depth of penetration [1]. However, the field of engineering protection lacks the formula to calculate the penetration depth of ceramicconcrete composite targets. Therefore, this paper mainly uses the differential protection coefficient to qualitatively analyze the antipenetration performance of FC-RPC targets.

5.1. Penetration Depth of RPC Target. The test used the residual penetration depth measurement method, also known as the DOP (depth of penetration) method. When the projectile penetrates the FC-RPC target at a certain speed, the projectile penetrates the FC target firstly and then penetrates the RPC target behind the FC target. The antipenetration performance of FC targets is evaluated by 
measuring the residual penetration depth of the projectile in the RPC target. Therefore, a clear antipenetration performance of an RPC target is the premise of the application of the DOP method.

Although the projectiles penetration effect research of high strength concrete has attracted much attention and there are a variety of formulas that have been proposed for calculating the penetration depth of high strength concrete targets, the formulas that are widely used and of high precision are few in number. Wang et al. [11] proposed a penetration depth calculation formula for RPC that takes the influence of the mass, shape, and velocity of the projectile and the strength, density, fracture toughness, and deformation wave velocity of the projectile into account. The reliability of the formulae is proved by repeated testing. The formula is expressed as

$$
h=\frac{M}{d^{2}} \lambda_{1} \lambda_{2} K_{\mathrm{q}} v
$$

where $M$ is the mass of the projectile; $d$ is the diameter of the projectile; $v$ is the impact velocity; $K_{\mathrm{q}}=1 /\left(\rho_{0} c_{\mathrm{p}}\right)$ is the penetration coefficient, where $\rho_{0}$ and $c_{\mathrm{p}}$ are the density and wave speed of RPC, respectively; and the shape factor $\lambda_{1}$ is defined by

$$
\lambda_{1}=\frac{2 \sqrt{1+4\left(l_{\mathrm{d}} / d\right)^{2}}}{\pi\left(1+2 \mu\left(l_{\mathrm{d}} / d\right)\right)^{2}},
$$

where $l_{\mathrm{d}}$ is the length of the projectile head; $\mu$ is the friction coefficient between the projectile and concrete; and $\lambda_{2}$ is defined by

$$
\lambda_{2}=\left(1-\eta \sqrt[4]{\frac{d}{2 l}}\right)
$$

where $\eta$ is a constant 0.46 , and $l=K_{\mathrm{c}} / \tau_{\mathrm{s}}^{\mathrm{e}}$, where $K_{\mathrm{c}}$ and $\tau_{\mathrm{s}}^{\mathrm{e}}$ are the fracture toughness and shear strength of RPC, respectively.

The results of the confirmatory test in [11] are shown in Figure 23, and the results of the formula are in good agreement with the experimental results. The mechanical properties of the RPC material used in this paper are very close to those in [11] because of the use of the same mixing ratio. Therefore, the penetration depths of the RPC targets in this paper could be calculated using formula (14), which results in $294 \mathrm{~mm}, 273 \mathrm{~mm}$, and $270 \mathrm{~mm}$, respectively. The formula results are in good agreement with the numerical results, as shown in Table 11.

\subsection{Differential Protection Factor of the FC-RPC Target.} The mass protection factor and differential protection factor are typically used to analyze the antiballistic performance of the composite target in armor systems [5]. The mass protection factor focuses on describing the antiballistic performance of the composite target considering the mass factor. However, the mass factor of an engineering protection material is secondary to the antipenetration performance of the material. Therefore, the differential protection factor focusing on describing the

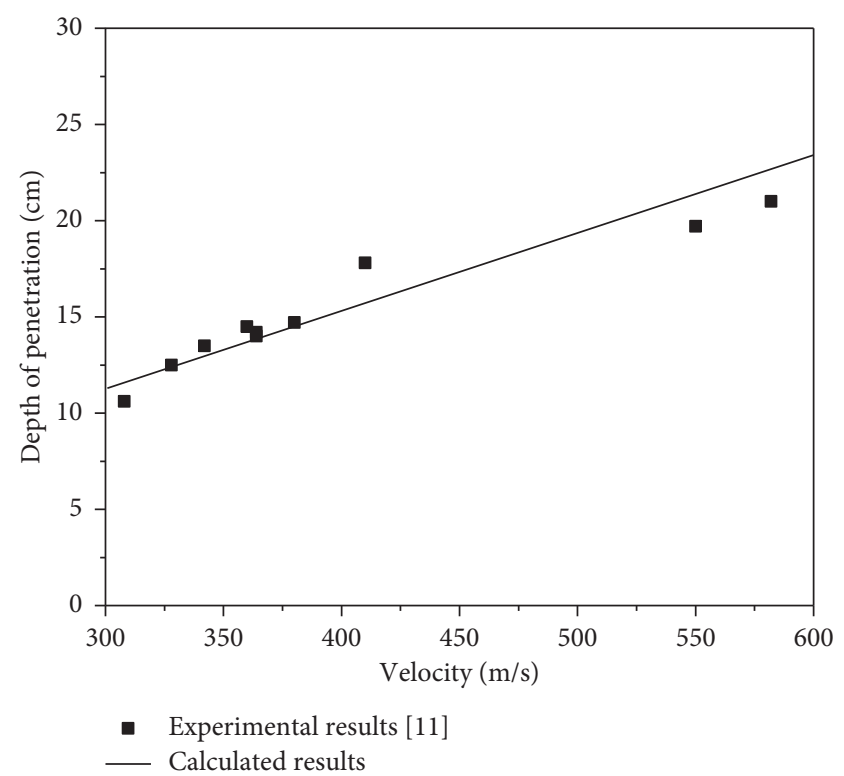

Figure 23: The experimental data of the RPC target.

antiballistic performance of FC targets is more suitable for evaluating the antipenetration performance of FC-RPC targets. Feng et al. [19] had successfully cited the differential protection factor to evaluate the antipenetration performance of the steel fiber-reinforced concretearmored composite target. To further quantitatively analyze the influence of FC target thickness on the antipenetration performance of FC-RPC targets, this paper also introduced the differential protection factor to evaluate the antipenetration performance of FC-RPC targets, and the formula is expressed as

$$
\Delta e_{\mathrm{c}}=\frac{\rho_{\mathrm{r}}\left(h_{2}-h_{\mathrm{q} 2}\right)}{\rho_{\mathrm{c}} h_{1}},
$$

where $\rho_{\mathrm{r}}$ is the density of RPC, $\rho_{\mathrm{c}}$ is the density of ceramic, $h_{2}$ is the penetration depth in the RPC target by formula or numerical simulation, $h_{1}$ is the thickness of the FC target, and $h_{\mathrm{q} 2}$ is the residual penetration depth in the RPC target.

To compare with the test results, assume that the initial impact velocity was $375 \mathrm{~m} / \mathrm{s}$ (average velocity in the test) and that the thickness of the FC target changed from $60 \mathrm{~mm}$ to $160 \mathrm{~mm}$. The differential protection factors of FC-RPC targets were calculated by numerical simulation results, which are summarized in Table 12. The differential protection factor decreases with the thickness of the FC target, but the relationship between them is nonlinear, which is shown in Figure 24. The numerical simulation results agree with the test results well.

\section{Conclusion}

Although the number of experiments in the paper was limited, some important damage phenomena have been obtained, some qualitative conclusions could be analyzed, and the effects of fiber layers were analyzed in detail with numerical simulation. In summary, based on the discussion 
TABLE 11: Comparisons of formula and numerical simulations on penetration depths of RPC targets.

\begin{tabular}{lcccc}
\hline No. & Velocity & Formula results $(\mathrm{mm})$ & Numerical results $(\mathrm{mm})$ & Relative error $(\%)$ \\
\hline 1 & 397 & 297 & 303 & 2.0 \\
2 & 367 & 273 & 282 & 3.3 \\
3 & 365 & 270 & 278 & 3.0 \\
\hline
\end{tabular}

TABLE 12: Differential protection factors of FC-RPC targets.

\begin{tabular}{lcccc}
\hline Case & $h_{1}(\mathrm{~mm})$ & $h_{2}(\mathrm{~mm})$ & $h_{\mathrm{q} 2}(\mathrm{~mm})$ & $\Delta e_{\mathrm{c}}$ \\
\hline 1 & 60 & 285 & 173 & 1.42 \\
2 & 80 & 285 & 142 & 1.36 \\
3 & 100 & 285 & 110 & 1.33 \\
4 & 120 & 285 & 78 & 1.31 \\
5 & 140 & 285 & 45 & 1.30 \\
6 & 160 & 285 & 12 & 1.30 \\
\hline
\end{tabular}

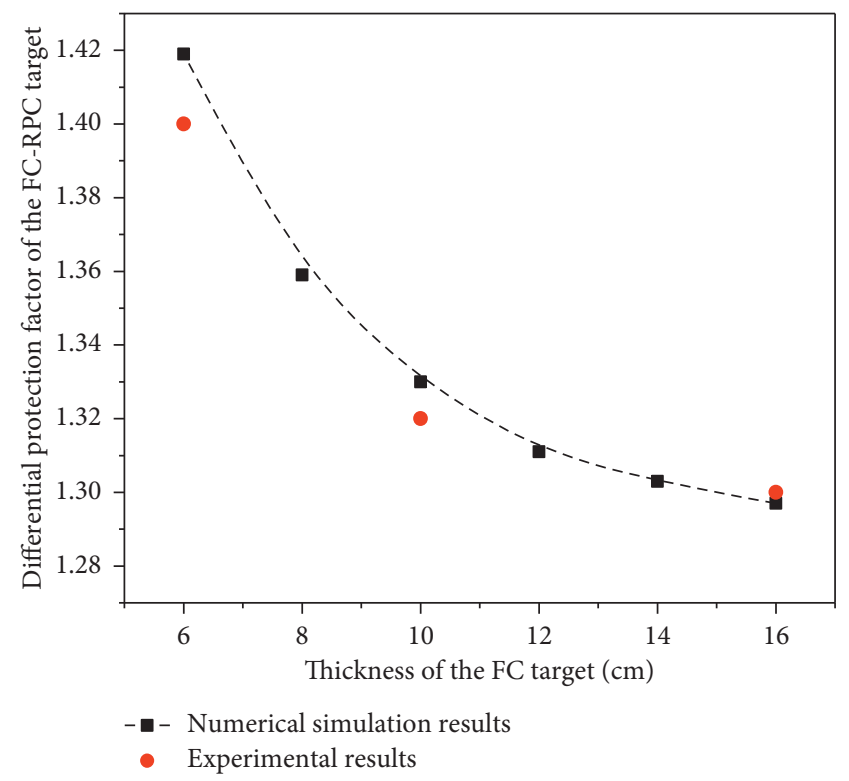

Figure 24: The differential protective factor of the FC-RPC target.

above, a number of conclusions could be made concerning the experiment and simulation results of the antipenetration performance of the FC-RPC target.

(1) Ceramic materials were successfully applied to protective structures in the form of FC-RPC composite structures in this paper. The FC-RPC target has excellent antipenetration performance, which can be validated from the damage of projectiles and targets. The antipenetration ability of the FC-RPC target increase with the thickness of the FC target.

(2) The combined model could reasonably account for the influence of the fiber layer on the composite target, and the calculated results were in good agreement with the experimental results. The numerical simulation results show that the antipenetration performance of FC-RPC target was much high than that of normal concrete target.
(3) The antipenetration performance of the FC-RPC targets was further evaluated by the differential protection factor, which was nonlinear decreasing with the increase of the thickness of the FC target.

\section{Data Availability}

The data used to support the findings of this study are available from the corresponding author upon request.

\section{Conflicts of Interest}

The authors declare that there are no conflicts of interest regarding the publication of this paper.

\section{Acknowledgments}

The authors would like to acknowledge the financial support from the National Natural Science Funds of China (Grant no. 51478466).

\section{References}

[1] H. Q. Ren, C. M. Mu, C. R. Liu et al., Penetration Effect of Precision Guided Weapons and Engineering Protection, The Science Press, Beijing, China, 2016.

[2] J. Feng, W. Sun, Z. Liu et al., "An armour-piercing projectile penetration in a double-layered target of ultra-highperformance fiber reinforced concrete and armour steel: experimental and numerical analyses," Materials \& Design, vol. 102, pp. 131-141, 2016.

[3] C. Y. Cui, R. Hou, H. Y. Xia et al., "Perforation resistance of corrugated metallic sandwich plates filled with reactive powder concrete: experiment and simulation," Composite Structures, vol. 127, pp. 426-435, 2015.

[4] Y. L. Wang, D. G. Tang, W. X. Chen et al., "Experimental and analytical study on the penetration of corundum-rubble concrete subjected to projectile impact," Shock and Vibration, vol. 2017, Article ID 1396567, 10 pages, 2017.

[5] V. Hohler, A. J. Stilp, and K. Weber, "Hypervelocity penetration of tungsten sinter-alloy rods into aluminum," International Journal of Impact Engineering, vol. 17, no. 1-3, pp. 409-418, 1995.

[6] D. Sherman, "Impact failure mechanisms in alumina tiles on finite thickness support and the effect of confinement," International Journal of Impact Engineering, vol. 24, no. 3, pp. $313-328,2000$.

[7] R. R. Franzen, D. L. Orphal, and C. E. Anderson, "The influence of experimental design on depth-of-penetration (DOP) test results and derived ballistic efficiencies," International Journal of Impact Engineering, vol. 19, no. 8, pp. 727-737, 1997.

[8] D. Sherman and T. Ben-Shushan, "Quasi-static impact damage in confined ceramic tiles," International Journal of Impact Engineering, vol. 21, no. 4, pp. 245-265, 1998. 
[9] C. E. Anderson and B. L. Morris, "The ballistic performance of confined $\mathrm{Al}_{2} \mathrm{O}_{3}$ ceramic tiles," International Journal of Impact Engineering, vol. 12, no. 2, pp. 167-187, 1992.

[10] R. Zaera, S. Sánchez-Sáez, J. L. Pérez-Castellanos, and C. Navarro, "Modelling of the adhesive layer in mixed ceramic/metal armours subjected to impact," Composites Part A: Applied Science and Manufacturing, vol. 31, no. 8, pp. 823-833, 2000.

[11] D. R. Wang, T. Ge, Z. P. Zhou et al., "Investigation of calculation method for anti-penetration of reactive powder steel fiber conc rete (RPC)," Explosion and Shock Waves, vol. 26, no. 4, pp. 367-372, 2006, in Chinese.

[12] Y. S. Tai, "Flat ended projectile penetrating ultra-high strength concrete plate target," Theoretical and Applied Fracture Mechanics, vol. 51, no. 2, pp. 117-128, 2009.

[13] Livermore Software Technology Corporation, LS-DYNA User's Manual Version 971, Livermore Software Technology Corporation, Livermore, CA, USA, 2013.

[14] T. J. Holmquist, G. R. Johnson, and W. H. Cook, "A computational constitutive model for concrete subjected to large strains, high strain rates, and high pressures," in Proceedings of 14th International Symposium on Ballistics, pp. 1-10, Quebec, Canada, September 1993.

[15] J. Ning, H. Ren, T. Guo, and P. Li, "Dynamic response of alumina ceramics impacted by long tungsten projectile," International Journal of Impact Engineering, vol. 62, pp. 6074, 2013.

[16] G. R. Johnson and W. H. Cook, "Fracture characteristics of three metals subjected to various strains, strain rates, temperatures and pressures," Engineering Fracture Mechanics, vol. 21, no. 1, pp. 31-48, 1985.

[17] G. R. Johnson and T. J. Holmquist, "An improved computational constitutive model for brittle materials," in High Pressure Science and Technology-1993, pp. 981-984, AIP Press, New York, NY, USA, 1994.

[18] X. H. Gu, X. M. Wang, H. W. Chen et al., "Experimental studies on kinetic projectile's direct penetrations with lowspeed against reinforced concrete targets," Journal of Nanjing University of Science and Technology, vol. 30, no. 1, pp. 1-4, 2006, in Chinese.

[19] J. Feng, W. W. Sun, Z. L. Liu et al., "Experiments and numerical simulation of penetration resistance of steel fiber reinforced concrete target backed by steel plate," Acta Armamentar, vol. 38, no. 6, pp. 1041-1050, 2017, in Chinese. 


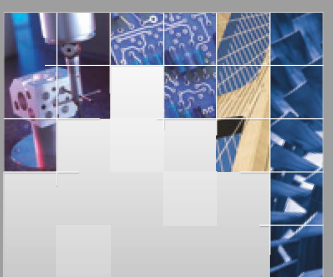

\section{Enfincering}
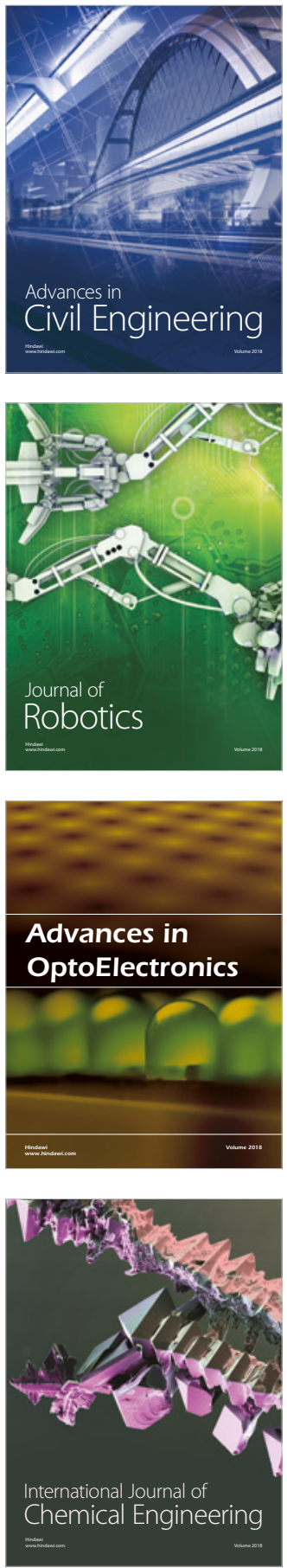

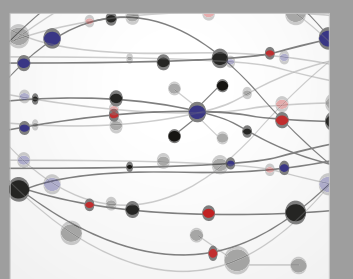

\section{Rotating \\ Machinery}

The Scientific World Journal

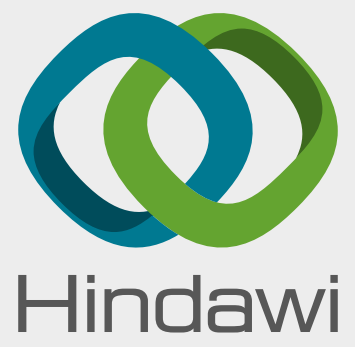

Submit your manuscripts at

www.hindawi.com
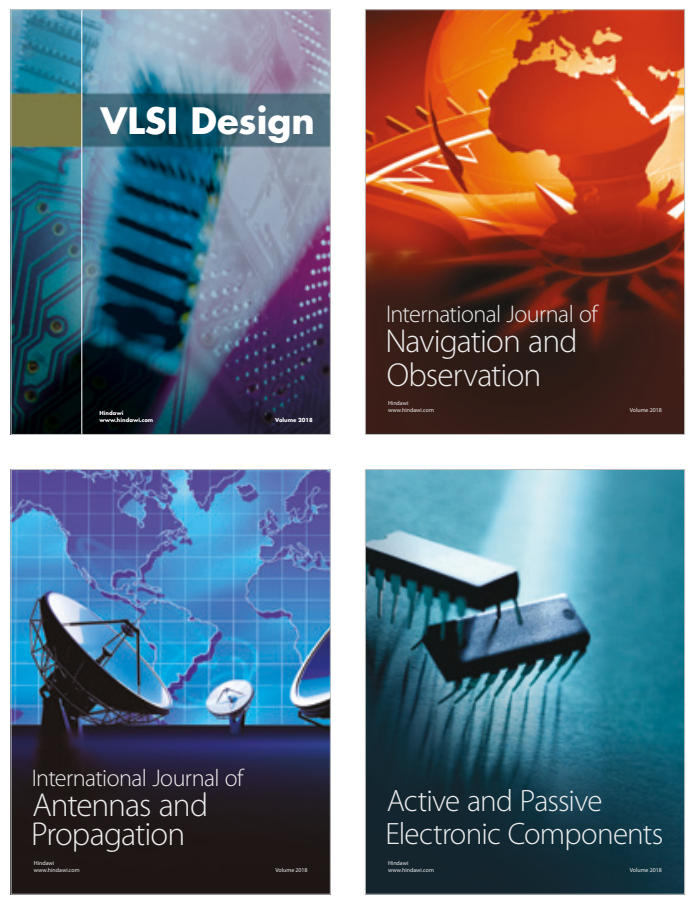
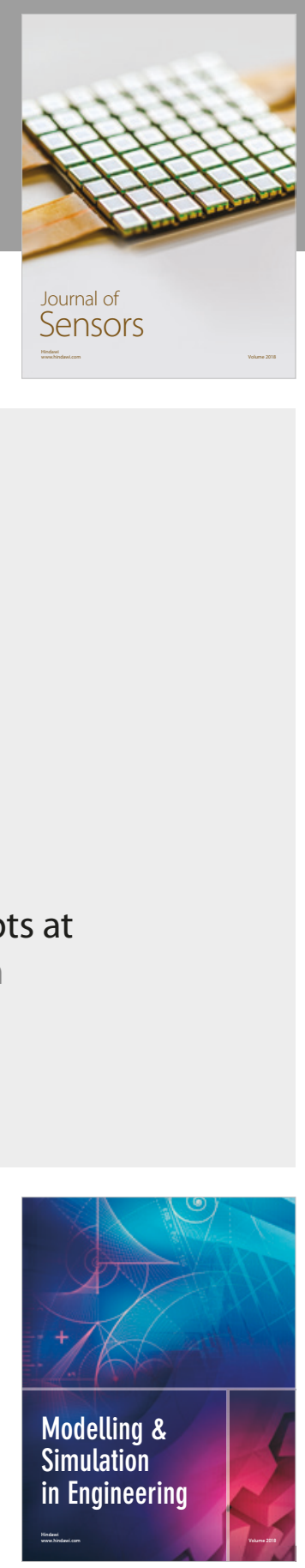

\section{Advances \\ Multimedia}
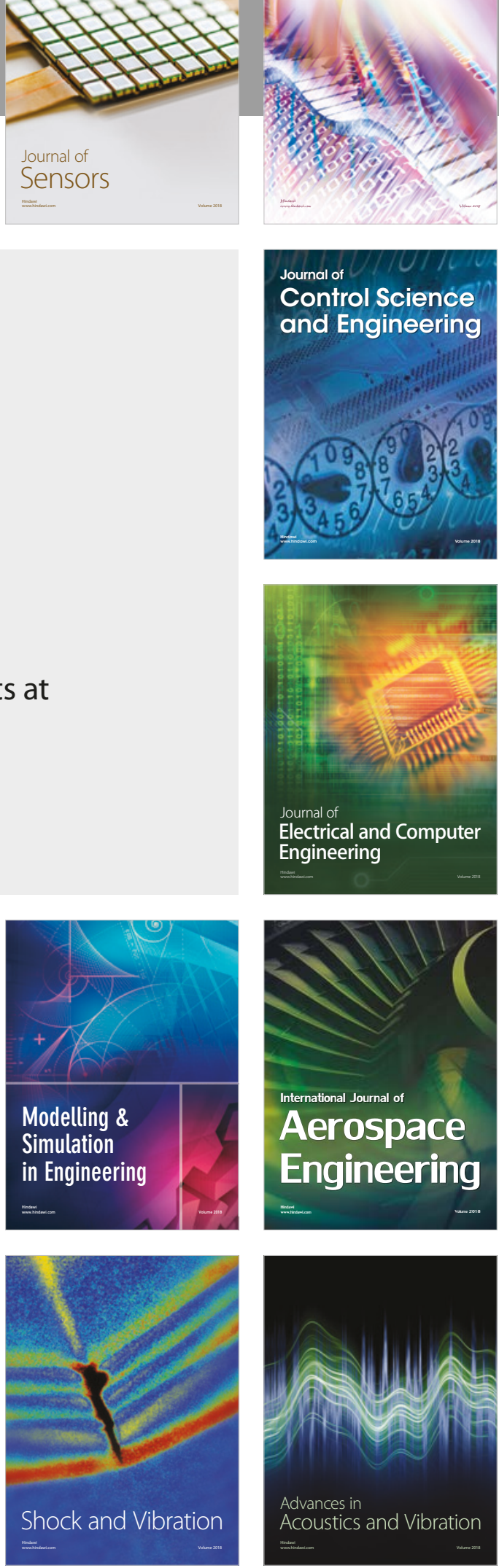